II. Guidelines for Routine Prenatal and Postpartum Care 



\title{
3. The First Prenatal Visit
}

\author{
MARY LEE BARRON | KELLY D. ROSENBERGER | JANET THORLTON
}

\section{General Guidelines}

The American Academy of Pediatrics (AAP) and the American College of Obstetricians and Gynecologists (ACOG) describe prenatal care as a comprehensive care program involving a coordinated approach to medical care and psychosocial support that optimally begins before conception and extends throughout the antepartum period (AAP \& ACOG, 2017). Comprehensive prenatal care is composed of the following elements: (a) preconceptional care, (b) prompt diagnosis of pregnancy, (c) initial prenatal evaluation, and (d) follow-up prenatal visits. Ongoing maternal-fetal assessment, education and support for the pregnant individual, preparation for parenting, and promotion of a positive physical and emotional family experience are all part of quality prenatal care.

\section{A. BACKGROUND}

1. National goals from the Centers for Disease Control and Prevention (CDC) for promoting prenatal care are as follows:

a. To increase the percentage of pregnant individuals who receive timely comprehensive screenings for risk factors

b. To increase the percentage of pregnant individuals who receive timely prenatal counseling and education as outlined in the guideline

c. To increase the number of first-trimester patients who have documentation of counseling about appropriate aneuploidy screening

d. To increase the percentage of vaginal birth after cesarean (VBAC)eligible individuals who receive documented education describing risks and benefits of VBAC

e. To increase the rate of appropriate interventions for identified change in status in individuals with preterm birth risk factors (National Clearinghouse Guidelines, 2012)

B. MEDICAL AND SURGICAL HISTORY, INCLUDING HEALTH MAINTENANCE INFORMATION

1. Endocrine disease: thyroid or diabetes mellitus

2. Hypertension

3. Pulmonary disease, asthma

4. Cardiac disease

5. Anemia, thalassemia, and hemoglobinopathies

6. Kidney or urinary tract disease, repeated urinary tract infection (UTI), and bacteriuria

7. Cancer

8. Seizure disorder

9. Psychiatric or emotional disorder 
10. Hepatitis or liver disease

11. HIV or AIDS

12. Autoimmune disease

13. Deep vein thrombosis (DVT), pulmonary embolism (PE), clotting disorder

14. Prior blood transfusions

15. Past surgery

\section{OBSTETRIC AND GYNECOLOGIC HISTORY}

1. Terminology

a. Two-digit system

i. Gravida: number of pregnancies, including current

ii. Para: number of pregnancies that resulted in the birth of a baby having reached viability (usually past 20 weeks)

b. Five-digit system

i. Gravida: number of pregnancies, including current

ii. Term: number of term ( $>37$ weeks) pregnancies

iii. Preterm: number of preterm births (past age of viability and $<37$ weeks)

iv. Abortion: number of pregnancies ending in spontaneous or elective abortion (less than the age of viability)

v. Living children: number of children currently alive

2. Menstrual history

3. Family planning history

4. Pap smear history

5. History of sexually transmitted infections (STIs)

6. Previous preterm labor and/or birth

7. Previous pregnancy loss (either spontaneous or elective)

8. Previous ectopic pregnancy

9. Previous cesarean birth

10. Previous low birth weight or macrosomic infant

11. Previous stillborn or neonatal death

12. Previous infant with congenital anomaly, neurological deficit, birth injury

13. Preeclampsia, eclampsia, HELLP (hemolysis, elevated liver enzymes, low platelet count) syndrome

14. Uterine fibroids

15. Rh negative

16. Cervical cerclage or history of incompetent cervix

17. Previous postpartum hemorrhage

18. Gynecologic surgery or breast problems

D. PSYCHOSOCIAL HISTORY

1. Age

2. Marital status

3. Educational level

4. Economic status

5. Religious and cultural beliefs, including whether blood transfusion would be acceptable and whether there are gender restrictions for obstetrics care provider

6. Health maintenance habits

7. Smoking

8. Alcohol consumption

9. Occupation/job 
10. Heavy lifting and/or long periods of standing

11. Support systems/household composition

12. Safety issues (e.g., domestic or intimate partner violence [IPV], weapons in the home)

13. Pets

14. Late entry into prenatal care

\section{E. IMMUNIZATIONS/IMMUNE STATUS}
1. Rubella
2. Hepatitis A and B
3. Varicella
4. Tetanus or Tdap (tetanus, diphtheria, and pertussis)
5. Polio
6. Influenza
7. Tuberculosis (TB)

\section{F. DRUG HISTORY}

1. Over-the-counter (OTC) medications, including nonsteroidal antiinflammatory drugs, vitamins, and botanical use

2. Current prescription medications

3. Illicit/illegal drug use

\section{G. NUTRITIONAL STATUS}

1. Height, weight, body mass index (BMI), and prepregnancy weight

2. Eating habits and usual dietary routine (use 1-to 3-day recall)

3. Eating of nonfood substances

4. Food allergies

5. Caffeine intake

6. Artificial sweetener use

7. Food safety

8. Exercise habits

9. Who does the cooking at home?

10. Risk factors for poor nutrition:
a. Adolescence
b. Low income
c. Cigarette smoking
d. Frequent dieting
e. Vegan diet
f. Pica
g. High parity
h. Mental illness, including depression
i. Use of certain medications such as phenytoin
j. Intellectual disability
k. Chronic diseases
1. Eating disorders

11. Screening for nutritional risk: Based on the 1-to 3-day recall, the nurse practitioner (NP) should assess whether the individual is at high risk nutritionally. If it is determined that the patient is undernourished, underweight, or nutritionally stressed, then active management is indicated (King et al., 2015). If the NP works with a dietician, the patient should be referred. However, many insurers only cover one visit. So, the NP should be prepared to spend time covering nutritional management.

a. Undernourished: an individual who is deficient in protein intake for pregnancy requirements 
b. Underweight: $\geq 5 \%$ below ideal body weight

c. Nutritionally stressed: pernicious vomiting, short interval between pregnancies $(<1$ year apart), poor obstetrical history, failure to gain $10 \mathrm{lbs}$. by the 20th week of gestation, serious emotional upset or problems

\section{H. GENETIC HISTORY}

(see Chapter 2)

1. Tay-Sachs disease

2. Sickle cell disease (SCD) or trait

3. Phenylketonuria (PKU)

4. Cystic fibrosis

5. Hemophilia, muscular dystrophy, Huntington's chorea

6. Intellectual disability, Down syndrome, fragile $X$

7. Birth defects, including cardiac and neural tube defects

8. Celiac disease

9. Myotonic dystrophy

10. Ethnic background: Ashkenazi Jewish, African American, Mediterranean, Asian

\section{EXPOSURE TO POTENTIAL TERATOGENS}

1. Metals (lead or mercury)

2. Organic solvents and their fumes

3. Gases, carbon monoxide

4. Ionizing radiation

5. Pollutants

6. Secondhand smoke

7. Pesticides, herbicides

8. Lead paint

9. Plastics, vinyl monomers

10. Hyperthermia, use of hot tubs

11. Recent travel history for potential teratogenic exposures (may be infectious or others)

\section{J. FAMILY MEDICAL HISTORY}

1. Autoimmune disorders such as lupus, rheumatoid arthritis, rashes, and arthralgias

2. Intellectual disability

3. Psychiatric disorders such as schizophrenia, depression, and bipolar disease

4. Diabetes

5. Polycystic ovarian syndrome (PCOS)

6. Hypertension

7. Obstetrical conditions such as preeclampsia

8. Fetal or neonatal death in a family member

9. Substance abuse in family members

\section{Screening Tools}

\section{A. SUBSTANCE USE AND ABUSE}

1. Because substance abuse or chemical dependency can adversely affect the health of the patient and the fetus, it is essential to include drug use 
assessment and education strategies in prenatal and preventative healthcare encounters.

2. The substance-use risk profile pregnancy scale

a. Have you ever smoked marijuana?

b. In the month before you knew you were pregnant, how many beers, how much wine, or how much liquor did you drink?

c. Have you ever felt that you needed to cut down on your drug or alcohol use?

Scoring: Answering yes to one question = moderate risk; answering yes to two or three questions $=$ high risk of having a positive screen for alcohol or illicit drug use

\section{B. TOBACCO USE}

1. Counseling interventions have been shown to increase cessation rates. One evidence-based approach is the "five As." In practices that have used the five As approach, quit rates among pregnant individuals have risen by $>30 \%$ (Martin et al., 2006) and more recently, over $23 \%$, specifically in individuals enrolled in Women, Infants, and Children (WIC; Olaiya et al., 2015). This approach to smoking cessation is easily integrated into prenatal care.

a. Ask: Ask the patient to choose a statement that best describes smoking status.

b. Advise: Ask permission to share the health message about smoking during pregnancy.

c. Assess: Readiness to change

d. Assist: Briefly explore problem-solving methods and skills for smoking cessation.

e. Arrange: Let the patient know that you will be following up on each visit; assess smoking status at subsequent prenatal visits; affirm efforts to quit (U.S. Preventive Services Task Force [USPSTF], 2021).

\section{DEPRESSION}

1. There are multiple depression screening tools available, with most taking no more than 10 minutes to complete. Examples of highly sensitive screening tools include the Edinburgh Postnatal Depression Scale, Center for Epidemiologic Studies Depression Scale, Beck Depression InventoryII, Postpartum Depression Screening Scale, and the Patient Health Questionnaire. However, the two-item screening measure "Over the past 2 weeks have you felt down, depressed, or hopeless?" and "Over the past 2 weeks, have you felt little interest in doing things?" is a sufficient and rapid way to begin identifying individuals at high risk for depression in prenatal care settings. This two-item screening tool, if positive, is then followed by the nine-item tool (PHQ9). "Failure to identify women with symptoms of depression is not a lack of sufficiently sensitive and brief screening measures; rather, it could be a failure to integrate brief depression screening questions such as these into prenatal interviews" (Jesse \& Graham, 2005, p. 44).

\section{INTIMATE PARTNER VIOLENCE}

1. There are a variety of tools available to screen for IPV(see www.nnvaw i.org/assessment.htm). There is no evidence that one screening tool is better than another. The first question to ask is whether the patient is safe at home, particularly if injuries are present. The routine history-taking procedure in which a standardized screening protocol is integrated increases 
identification, documentation, and referral for IPV. Victims are found among individuals of all ages, socioeconomic classes, and ethnicities. Married individuals living apart from their spouses are more likely to be victims of rape, physical assault, and/or stalking. Separated, divorced, and cohabitating individuals are at a greater risk for IPV. However, there is no single profile of the individual who suffers abuse, and the abuse is likely to continue or escalate during pregnancy (AAP \& ACOG, 2017).

2. If abuse is identified or suspected, intervention is essential. At a minimum, referral sources and educational material should be readily available (including phone numbers to a shelter and the police). Documentation (including patient quotes) should include the frequency and severity of present and past abuse, location and extent of injuries, treatments, and interventions. Discuss a plan of escape and document whether shelter assistance was declined or accepted by the patient. Counseling and intervention can reduce IPV and improve pregnancy outcome. See Section VI.M (of this chapter) and Appendix B for screening tools.

\section{Physical Examination}

\section{A. AREAS OF ASSESSMENT}

1. Vital signs, height and weight, and prepregnancy weight and BMI

2. Skin, hair, and nails

3. Head, neck, and thyroid

4. Eyes, ears, nose, mouth, and throat

5. Chest and lungs

6. Heart

7. Abdomen, including fundal height as appropriate

8. Pelvic examination
a. External genitalia/perineum
b. Vagina
c. Cervix
d. Uterus
e. Adnexa
f. Clinical pelvimetry
g. Rectal or rectovaginal examination as appropriate

9. Microscopic wet prep of vaginal secretions as appropriate

\section{TABLE 3.I AREAS OF ASSESSMENT AND COMMENTS}

\begin{tabular}{|c|c|}
\hline $\begin{array}{l}\text { AREA OF } \\
\text { ASSESSMENT }\end{array}$ & PREGNANCY-RELATED FINDING/COMMENTS \\
\hline $\begin{array}{l}\text { Physical } \\
\text { characteristics }\end{array}$ & $\begin{array}{l}\text { Physical characteristics such as height, weight, and pelvimetry data can } \\
\text { influence pregnancy course and birth, that is, patients of small stature; } \\
\text { android-shaped pelvis }\end{array}$ \\
\hline Prepregnancy BMI & $\begin{array}{l}\mathrm{BMI} \text { is the strongest predictor of maternal weight gain occurring outside of } \\
\text { the IOM recommendations. Low } \mathrm{BMI}=\text { highest risk for inadequate weight } \\
\text { gain; high } \mathrm{BMI}=\text { highest risk for excessive weight gain }\end{array}$ \\
\hline $\begin{array}{l}\text { Cardiovascular } \\
\text { changes: blood } \\
\text { pressure and } \\
\text { pulse }\end{array}$ & $\begin{array}{l}\text { Blood volume increases until about } 30-34 \text { weeks and then plateaus; cardiac } \\
\text { output increases and peaks at } 25-30 \text { weeks gestation at } 30 \%-50 \% \text { above } \\
\text { prepregnant levels } \\
\text { Pulse rate increases by up to } 10-15 \text { bpm; blood pressure decreases } \\
5-10 \mathrm{mmHg} \text {, reaching the lowest point during the second trimester and } \\
\text { then gradually increases to near prepregnant levels at term }\end{array}$ \\
\hline
\end{tabular}




\section{TABLE 3.I AREAS OF ASSESSMENT AND COMMENTS (CONTINUED)}

\section{AREA OF \\ ASSESSMENT PREGNANCY-RELATED FINDING/COMMENTS}

Femoral venous pressure slowly rises with uterine expansion, which leads to a tendency toward venous stasis, dependent edema, and varicose vein formation in the legs, vulva, and rectum. In addition, a reduction of plasma colloid osmotic pressure resulting from reduced albumin promotes lower extremity edema

Postural hypotension and supine hypotensive syndrome may occur as a result of uterine pressure on the vena cava. Exaggerated splitting of $\mathrm{SI}$; systolic murmurs are common due to volume expansion

\begin{tabular}{|c|c|}
\hline Hair & $\begin{array}{l}\text { There is a decrease in the rate of growth and the number of hair follicles in } \\
\text { the resting or dormant phase. During the postpartum phase, the number } \\
\text { of hair follicles in the resting phase increases sharply so that the patient } \\
\text { may notice increased shedding of hair for } 1-4 \text { months. Nearly all hair is } \\
\text { replaced within } 6 \text { months }\end{array}$ \\
\hline Skin & $\begin{array}{l}\text { Hyperpigmentation of the face (chloasma), areola, and nipples; linea nigra, } \\
\text { striae gravidarum, and spider nevi are common; rubor of palms due to } \\
\text { estrogen levels; occasionally intrahepatic cholestasis will lead to pruritus, } \\
\text { which resolves after delivery }\end{array}$ \\
\hline Eyes & $\begin{array}{l}\text { Intraocular pressure decreases; corneal sensitivity increases; slight thickening } \\
\text { of the cornea that disappears by } 6 \text { weeks postpartum; may make it difficult } \\
\text { to wear contact lenses comfortably }\end{array}$ \\
\hline Nose & $\begin{array}{l}\text { Vascular dilation of the nasal mucous membranes due to estrogen may cause } \\
\text { stuffiness and nosebleeds }\end{array}$ \\
\hline Dentition/gums & $\begin{array}{l}\text { Saliva production increases; no demineralization of the teeth; gum tissue } \\
\text { becomes hyperemic, spongy, and swollen, which may lead to gingivitis as } \\
\text { pregnancy immunosuppression hinders the normal response to bacteria } \\
\text { that causes periodontal infections }\end{array}$ \\
\hline Thyroid & Slightly enlarged because of glandular hyperplasia \\
\hline Chest and lungs & $\begin{array}{l}\text { Adaptive changes to improve gaseous exchange and promote fetal } \\
\text { circulation: respiratory center in the brain is more sensitive to } \mathrm{CO}_{2} \text {; } \\
\text { dyspnea may occur; lower ribs flare, which increases tidal volume by } 30 \%- \\
40 \% \text {; slightly increased respiratory rate. Systolic murmurs are common due } \\
\text { to volume expansion }\end{array}$ \\
\hline Breasts & $\begin{array}{l}\text { Increase in size, nodularity, and sensitivity due to estrogen and progesterone; } \\
\text { alveolar cells become secretory; bra size increases }\end{array}$ \\
\hline $\begin{array}{l}\text { Gastrointestinal } \\
\text { abdomen }\end{array}$ & $\begin{array}{l}\text { Changes in sense of taste are common. Tone and motility of smooth muscle } \\
\text { are lowered (due to progesterone). Gastric secretion of hydrochloric acid } \\
\text { and pepsin decreases. Delayed gastric emptying. Nausea, indigestion, reflux, } \\
\text { and constipation are common. Gallbladder is hypotonic and distended so } \\
\text { that gallstone formation may occur }\end{array}$ \\
\hline Musculoskeletal & $\begin{array}{l}\text { Joint relaxation due to influence of relaxin; mobility of the sacroiliac, } \\
\text { sacrococcygeal, and pubic joints increases; lordosis is common by third } \\
\text { trimester }\end{array}$ \\
\hline Neuro/reflexes & $\begin{array}{l}\text { Fainting or light-headedness common in the first trimester. Carpal tunnel } \\
\text { syndrome due to fluid retention; mild frontal headaches are common and } \\
\text { may be related to hormonal influences. Deep tendon reflexes become } \\
\text { more reactive with preeclampsia }\end{array}$ \\
\hline
\end{tabular}


TABLE 3.I AREAS OF ASSESSMENT AND COMMENTS (CONTINUED)

\begin{tabular}{|l|l|}
\hline $\begin{array}{l}\text { AREA OF } \\
\text { ASSESSMENT }\end{array}$ & PREGNANCY-RELATED FINDING/COMMENTS \\
\hline Pelvis & $\begin{array}{l}\text { Vagina: pink or dark pink; in multiparas, vaginal folds may become smooth } \\
\text { Cervix: softens, more readily bleeds, bluish color (Chadwick's sign); os closed } \\
\text { in nulliparas; external os may admit one fingertip in the multipara } \\
\text { Uterine size: initial enlargement in the anterior-posterior diameter, softening } \\
\text { of the isthmus (Hegar's sign); see Section III.D for further information } \\
\text { Adnexae: usually of normal size, nontender (however, a unilateral nontender } \\
\text { corpus luteum cyst may be present) }\end{array}$ \\
\hline Anus/rectum & Pressure from an enlarging uterus may cause hemorrhoids \\
\hline
\end{tabular}

BMI, body mass index; bpm, beats per minute; IOM, Institute of Medicine.

10. Back, spine, and extremities

11. Neurological examination, including deep tendon reflexes (Table 3.1)

\section{B. DEVELOPMENTAL DEFINITIONS AND TERMINOLOGY}

1. Preembryonic stage: First 14 days of human development. Synchronized development of the endometrium and embryo is necessary for successful implantation.

2. Ovum, zygote (fertilized ovum), morula (when cleavage occurs)

3. Blastocyst: After the cleavage has produced over 100 cells, the embryo is called a blastula. The blastula is usually a spherical layer of cells surrounding a fluid-filled or yolk-filled cavity with an inner cell mass that is distinct from the surrounding blastula. The total structure is the blastocyst. The inner cell mass subsequently forms the embryo, and the outer layer of cells, or trophoblast, later forms the placenta.

4. Implantation at 7 to 10 days after fertilization

5. Embryo (8 weeks), fetus (8 weeks until birth)

6. Trimester: First, conception to 13 weeks; second, 14 to 27 weeks; third, 28 weeks to birth (ACOG \& AAP, 2017).

\section{CONFIRMATION OF PREGNANCY}

1. Human chorionic gonadotropin (HCG) testing in urine or blood (Table 3.2)

2. Clinical landmarks: first-trimester bimanual examination of the uterus

3. Presence of the fetal heartbeat

\section{TABLE 3.2 BETA-HCG LEVEL (MIU/L) IN EARLY SINGLETON PREGNANCY AND ULTRASOUND FINDINGS}

\begin{tabular}{|c|c|c|}
\hline $\begin{array}{c}\text { APPROXIMATE } \\
\text { GESTATIONAL } \\
\text { AGE (WEEKS } \\
\text { FROM LMP) }\end{array}$ & $\begin{array}{c}\text { BETA-HCG LEVEL } \\
\text { (MIU/L) }\end{array}$ & $\begin{array}{c}\text { TYPICALTRANSVAGINAL } \\
\text { ULTRASOUND FINDING }\end{array}$ \\
\hline 5 & $\geq 1,000$ & Gestational sac \\
\hline 6 & $\geq 2,500$ & Yolk sac \\
\hline 7 & $\geq 5,000$ & Fetal pole \\
\hline 8 & $\geq 17,000$ & Fetal heartbeat \\
\hline
\end{tabular}

HCG, human chorionic gonadotropin; IU, international units; LMP, last menstrual period. 
4. Ultrasound confirmation of the presence of the gestational sac/embryo/ fetus

\section{DATING CRITERIA}

Accurate dating of the pregnancy is one of the most important clinical responsibilities.

1. Naegele's rule (dependent on a menstrual cycle of 28 days and an accurate date of the last menstrual period [LMP])

a. First day of LMP, subtract 3 months, add 7 days

b. Estimated date of delivery (EDD) wheel is a tool to use representing Naegele's rule

c. There are many due-date calculation apps available for smartphones or personal digital assistants (PDAs); these are based on a 28-day cycle

d. If the pregnancy resulted from ART (assisted reproductive technology), the ART-derived gestational age should be used to assign the EDD

2. Ultrasound is highly accurate for dating when performed in the first trimester. Accuracy for dating purposes diminishes with the progress of the pregnancy. Crown-rump length can be used for gestational age from 4 days up to 12 weeks. If ultrasound dating before 14 weeks varies by more than 7 days than dating by LMP, then the EDD should be changed to agree with ultrasound dating. Biparietal diameter (BPD) can be assessed at approximately 14 weeks and is useful until 26 weeks. BPD predicts EDD within 7 to 10 days. After 26 weeks, predicting EDD by BPD is less accurate, usually \pm 3 weeks.

3. Uterine size

a. Bimanual examination: This is an essential diagnostic tool to date early pregnancies. Accuracy of this estimate is generally considered to be \pm 2 weeks because uterine size is affected by fibroids, uterine position (i.e., retroflexed uterus), multiple gestation, and maternal obesity. Using a comparison to various fruit sizes is a rough mental benchmark that is clinically useful, especially for the inexperienced clinician.

i. 5-week size: small unripe pear

ii. 6-week size: small orange

iii. 8-week size: large navel orange

iv. 12-week size: grapefruit

b. Fundal height: An indicator of uterine size measuring from the symphysis pubis to the top of the fundus. Correlates with the weeks of gestation after 20 weeks within $\pm 2 \mathrm{~cm}$, that is, 22 weeks $= \pm 22 \mathrm{~cm}$. May be used up to 36 weeks. If it does not correlate, then an ultrasound exam for fetal growth may be indicated.

4. Serum beta-HCG testing: Serum beta-HCG levels are highly correlated with gestational age during early pregnancy. Beta-HCG can be detected as early as 8 days after the luteinizing hormone (LH) surge, when pregnancy occurs. The beta-HCG concentration in a normal intrauterine pregnancy rises in a curvilinear fashion during the first 6 weeks of pregnancy. BetaHCG then plateaus at approximately 100,000 IU/L. Doubling time for the hormone is from 48 hours for clinical decision-making purposes. The betaHCG concentration rises at a much slower rate in most, but not all, ectopic and nonviable intrauterine pregnancies. However, when the beta-HCG level exceeds 3,000 $\mathrm{mIU} / \mathrm{mL}$, the absence of a gestational sac strongly suggests that the pregnancy is abnormal.

5. Chadwick's, Goodell's, and Hegar's signs may support a diagnosis of pregnancy but are mainly of historical value and no longer used now that more accurate diagnostic tools are available. 


\section{A. SERUM TESTING}

1. Complete blood count (CBC): hematocrit (Hct), hemoglobin (Hgb), mean corpuscular volume (MCV), mean corpuscular Hgb concentration (MCHC), platelet count, and white blood cell (WBC)

a. The increased plasma volume, along with the increase in red blood cell (RBC) mass, ultimately expands the maternal blood volume by as much as $35 \%$ to $45 \%$, peaking at 32 weeks (Cunningham et al., 2014). Physiologic anemia describes the proportionately greater increase in plasma volume compared with the rise in RBCs. When Hgb levels are $<11 \mathrm{~g}$ and/or Hct levels are $<32 \%$, pathologic anemia is diagnosed. However, Hgb and Hct levels are lower in African American women compared with Caucasian women; therefore, the Institute of Medicine (IOM) recommends lowering the cutoff levels by $0.8 \mathrm{mg} / \mathrm{dL}$ for $\mathrm{Hgb}$ and $2 \%$ for Hct in this population.

b. The nonpregnant woman normally has a platelet count of 150,000 to $400,000 / \mathrm{mm}^{3}$. Although during normal pregnancy there is a progressive drop in the count, it rarely drops below the range for the nonpregnant woman. The decreased platelet count is due to increased utilization of platelets. A low platelet count is associated with pregnancy-induced hypertension, immunologic thrombocytopenic purpura, disseminated intravascular coagulation, acquired hemolytic anemia, septicemia, and lupus erythematosus (Cunningham et al., 2014).

c. The normal nonpregnant WBC ranges between 5,000 and $10,000 \mathrm{~mm}^{3}$. Duringpregnancy, theWBCincreases, yieldingarangeof 5,000 to $12,000 \mathrm{~mm}^{3}$ (Cunningham et al., 2014).

2. $\mathrm{ABO}$ and Rhesus (Rh) typing, antibody screen

a. Hemolytic disease of the fetus and newborn occur when blood incompatibilities between the pregnant individual and fetus exist. The potential for these incompatibilities exists in the following situations in which the maternal and fetal blood types differ.

i. The mother has type $\mathrm{O}$ blood; the fetus has type $\mathrm{A}, \mathrm{B}$, or $\mathrm{AB}$

ii. The mother is Rh negative; the fetus is $\mathrm{Rh}$ positive

iii. The mother is negative for some other RBC antigen, like Kell, for which the fetus is positive

b. Early identification of blood incompatibilities and appropriate medical and nursing management are essential to reducing severity of the disorder. Laboratory assessment at the first prenatal visit includes an antibody screen as well as blood type and Rh. An indirect Coombs test is most often used for the initial antibody screen because this test is sensitive to anti-Rh antibodies. Patients who test positive are then tested for the specific antibody and titer. Management in pregnancy is dependent on the degree to which the specific antibody is known to cause hemolytic disease in the fetus or newborn. Most cases of hemolytic disease are caused by $\mathrm{Rh}$ and $\mathrm{ABO}$ incompatibilities, with Rh-induced disease causing the most severe cases. The Rh antigens are grouped into three pairs: Dd, Cc, and Ee. The presence of D determines that the person is Rh positive. The absence of $\mathrm{D}$ determines that a person is $\mathrm{Rh}$ negative. $\mathrm{Rh}$ isoimmunization occurs only when Rh-positive erythrocytes enter a Rh-negative person's bloodstream, which then produce anti-D. Anti-D causes hemolytic disease in the Rh-positive fetus. Isoimmunization can result when a patient is transfused with improperly matched blood, or when an individual is exposed to fetal blood through miscarriage or 
abortion, an ectopic pregnancy, an amniocentesis, antepartal bleeding, or placental separation. In response to exposure to Rh-positive cells, the mother produces antibodies to the $\mathrm{Rh}$ antigen that have the potential to cause hemolytic disease in an Rh-positive fetus or newborn in future pregnancies. Specifically, fetal erythrocytes are destroyed by maternal antibodies that cross the placenta and enter fetal blood.

c. Cases that require follow-up include patients who are:

i. Blood type $\mathrm{O}$, positive antibody screen

ii. Rh negative, father is $\mathrm{Rh}$ positive

iii. Rh negative, father's type is unknown

d. Cases in which no follow-up is needed include patients who are:

i. Rh positive; blood group $A, B$, or $A B$ with negative antibody screen

ii. $\mathrm{Rh}$ negative; father is $\mathrm{Rh}$ negative; both have negative antibody screen

iii. Rh negative, Du positive

e. Fortunately, the process of Rh isoimmunization can usually be prevented with prenatal (at 28 weeks) and postpartum administration of Rho(D) immune globulin such as RhoGAM ${ }^{\circledR}$. Additional times when RhoGAM may be administered include any possible "leaking" of fetal blood into the maternal system:

i. During or after all pregnancies, including ectopic pregnancies and after early miscarriages

ii. After chorionic villus sampling, amniocentesis, cordocentesis

iii. After external cephalic version

iv. After an injury to the abdomen

f. The Rh blood group system is more complex than what has just been described. There are 35 other antibodies that delineate Rh antigens. Du replacing $\mathrm{D}$ is not uncommon and is found more frequently among African Americans. Rarely, a Du-positive mother carrying a D-positive fetus may produce anti-D, which in turn causes hydrops fetalis.

3. Serology: Either rapid plasma reagin (RPR) or venereal disease research laboratory (VDRL) with reflex microhemagglutination assay (MHA-TP) or fluorescent treponemal antibody (FTA-ABS)

a. A serologic test for syphilis should be performed on all pregnant patients at the first prenatal visit. In populations in which the amount of prenatal care delivered is not optimal, RPR card test screening (and treatment, if that test is reactive) should be performed at the time of confirmation of pregnancy. Individuals who are at high risk for syphilis, who live in areas of high syphilis morbidity, or who are previously untested should be screened again early in the third trimester (at approximately 28-32 weeks gestation) and at delivery (Centers for Disease Control and Prevention [CDC], 2021).

b. The VDRL and RPR designed to detect the presence of nonspecific reaginic antibodies elicited by the spirochete are relatively inexpensive, very sensitive, moderately nonspecific, and fast. The false-positive rate for pregnant individuals is $1 \%$ to $2 \%$ (Williamson \& Snyder, 2014). A high titer $(>1: 16)$ usually indicates active disease. A low titer $(<1: 8)$ indicates a biologic false-positive test in $90 \%$ of the cases or occasionally may be due to late or late latent syphilis. A titer is performed before treatment. A fourfold drop in the titer indicates a response to therapy. Treatment of primary syphilis usually causes a progressive decline (i.e., low titers) to a negative VDRL titer within 2 years. In secondary, late, or latent syphilis, low titers persist in approximately $50 \%$ of the cases 
after 2 years despite a fall in the titer. This does not indicate treatment failure or reinfection, and these patients are likely to remain positive even if retreated. Titer response is unpredictable in late or latent syphilis. Rising titer (four times) indicates relapse, reinfection, or treatment failure (Williamson \& Snyder, 2014).

c. False positives can occur in individuals with acute and chronic illnesses, such as TB, infectious mononucleosis, rheumatoid arthritis, collagen vascular diseases, chlamydia infection, and hepatitis (Williamson \& Snyder, 2014). The presence of anticardiolipin antibodies, which can trigger a reactive VDRL, is particularly significant in pregnancy.

d. The presence of Treponema pallidum is confirmed using either the FTA-ABS absorption test MHA-TP or Treponema pallidum antibodies to determine whether the individual has developed antibodies to the spirochete. A seropositive result indicates that the individual has been exposed to the spirochete and has developed antibodies. Because this test frequently remains positive after successful treatment, monitoring is accomplished using titers of the VDRL or RPR.

4. Rubella screening

a. The most frequently used test to detect rubella antibodies in serum is the hemagglutination inhibition test. Immunity is confirmed if the rubella antibody titer is 1:8 or more (Williamson \& Snyder, 2014). Persons who have an "equivocal" serologic test result should be considered susceptible to rubella.

5. Hepatitis screening

a. Hepatitis B virus (HBV): Pregnant individuals at risk for HBV infection should be vaccinated. To avoid misinterpreting a transient positive HBsAg result during the 21 days after vaccination, HBsAg testing should be performed before vaccine administration. All laboratories that conduct HBsAg tests should use a Food and Drug Administration (FDA)-cleared HBsAg test and perform testing according to the manufacturer's labeling, including testing of initially reactive specimens with a licensed neutralizing confirmatory test. Pregnant patients who are HBsAg positive should be reported to the local or state health department to ensure that they are entered into a case management system and that timely and appropriate prophylaxis is provided for their infants. Information concerning the pregnant patient's HBsAg status should be provided to the hospital in which delivery is planned and to the healthcare provider who will care for the newborn. In addition, household and sexual contacts of individuals who are HBsAg positive should be vaccinated. Patients who are HBsAg positive should be provided with, or referred for, appropriate counseling and medical management. Pregnant individuals who are HBsAg positive should receive information regarding hepatitis $\mathrm{B}$ that addresses:

i. Modes of transmission

ii. Perinatal concerns (e.g., breastfeeding is not contraindicated)

iii. Prevention of HBV transmission, including the importance of postexposure prophylaxis for the newborn infant and hepatitis $B$ vaccination for household contacts and sex partners

iv. Evaluation for and treatment of chronic HBV infection

b. Hepatitis $\mathrm{C}$ virus (HCV): No treatment is available for pregnant individuals infected with HCV. However, all patients with HCV infection should receive appropriate counseling and supportive care as needed. Because the vertical transmission is so low, routine screening of prenatal individuals is not warranted. No vaccine is available to prevent $\mathrm{HCV}$ 
transmission. HCV antibodies pass transplacentally to the infant, so testing for this antibody in the infant should be delayed until 18 months of age.

6. HIV (see Chapter 20)

a. The CDC recommends HIV screening for all individuals as a standard part of prenatal care to identify and treat HIV and to prevent transmission of HIV to infants. Patients who test positive for HIV and begin treatment early in their pregnancy reduce the risk of mother-to-child HIV transmission to $\geq 2 \%$.

b. Pregnant individuals are likely to get tested if their providers strongly recommend it. In a study of 1,362 pregnant patients, $93 \%$ of patients who felt their providers strongly recommended an HIV test decided to get tested.

c. Screening for HIV early in pregnancy, preferably at the first obstetrical visit, benefits both mothers and babies. Patients with HIV who start treatment early and maintain it throughout their pregnancy protect their own health and rarely pass HIV to their infants. Patients who have not been tested or have an increased risk for HIV should be tested in the third trimester.

d. It is never too late for pregnant individuals to get tested. Rapid HIV tests allow patients who arrive at delivery rooms with unknown HIV status to receive an HIV test. Preventive medications administered to the mother during labor, and to the infant after birth, can reduce the risk of mother-to-child HIV transmission to about $10 \%$. Some clinicians may also test a pregnant patient late in the third trimester of pregnancy.

7. Blood lead level

a. In 2019, the USPSTF concluded that the current evidence is insufficient to assess the balance of benefits and harms of screening for elevated blood lead levels in asymptomatic pregnant persons. The prevalence of elevated blood lead levels varies substantially among different communities and populations. Children living with mothers who have elevated levels are at higher risk for elevated lead levels, which lead to neurodevelopmental damage. Children and pregnant individuals share many of the same risk factors for lead exposure. The most predictive factor is living in a home that was built before 1960. Therefore, the NP should decide based on what is known regarding the community lead exposures. The prevalence of levels $>15 \mathrm{mcg} / \mathrm{dL}$ appears to be quite low in pregnant individuals. There is some evidence that mildly elevated lead levels during pregnancy are associated with small increases in antepartum blood pressure, but only limited evidence indicates that these levels have important adverse effects on reproductive outcomes.

8. Progesterone level may be considered for patients at high risk for preterm delivery and for those with first-trimester spotting or bleeding (see Chapter 15).

9. Thyroid function screening: Maternal and fetal complications are associated with both hypothyroidism and hyperthyroidism. The ACOG, the Endocrine Society, and the American Thyroid Association recommend testing for thyroid dysfunction if the pregnant individual has any of the following:

a. Symptoms of thyroid disease

b. Personal or family history of thyroid disease

c. Characteristics that are associated with developing overt hypothyroidism such as type 1 diabetes, goiter, amiodarone/lithium use, iodine deficiency, history of head, and neck radiation). See Chapter 23 for indepth information. 
10. Type 2 diabetes: Some clinicians universally screen with an $\mathrm{HbA} 1 \mathrm{C}$ at the initial prenatal visit and then again at 24 to 28 weeks. Others screen patients at risk with a random glucose ( $>200 \mathrm{mg} / \mathrm{dL}$ is abnormal) and subsequently, an $\mathrm{HbA1C}$ to confirm the diagnosis (see Chapter 16).

\section{B. PAP SMEAR}

1. Pregnancy is not a reason to do cervical screening. A Pap smear is done according to standardized guidelines at the first prenatal visit. However, if in the past 24 to 48 hours the pregnant individual has douched, had intercourse, or used a vaginal suppository, or there is evidence of vaginal or cervical infection, the Pap smear should be deferred until the next visit.

2. Pregnancy produces changes in the cervix that need to be taken into account when interpreting the results of a Pap smear. During pregnancy, the squamocolumnar junction increases in size. As the pregnancy progresses, squamous epithelium may replace columnar epithelium by a process called squamous metaplasia, which may be reflected in the Pap smear result. However, this migration of cells makes the process of colposcopy easier to do in pregnancy than in the nonpregnant state (Cunningham et al., 2014).

3. In pregnancy, the only diagnosis that alters management of an abnormal Pap smear is invasive cancer (ACOG, 2013; American Society for Colposcopy and Cervical Pathology, 2013). Patients with Pap results that are not likely to be associated with cancer (atypical squamous cells) may undergo colposcopy examination either during the pregnancy or at 6 to 12 weeks postpartum. For pregnant individuals with a low-grade squamous intraepithelial lesion, colposcopy is preferred, but deferring to 6 weeks postpartum is acceptable.

\section{URINE TESTING}

1. Prenatal screening for bacteriuria is essential because of the well-known association between preterm labor and UTI during pregnancy. A complete urinalysis (UA) is generally performed only once during a healthy, low-risk pregnancy at the first or second prenatal visit. Anatomic, physiologic, and hormonal changes predispose a pregnant individual to the development of pyelonephritis, one of the most common medical problems of pregnancy. Pregnant individuals with sickle cell trait or disease, high parity, and diabetes are more likely to develop bacteriuria. However, asymptomatic bacteriuria (ASB) is a major risk factor for the development of pyelonephritis. To screen for symptomatic UTI or ASB, a clean-catch midstream urine is required. The diagnosis of ASB or symptomatic UTI is usually based on a colony count of $\geq 100,000 / \mathrm{mL}$ of a particular organism on a freshly voided clean-catch midstream specimen. The pathogen responsible for $80 \%$ to $90 \%$ of infection is Escherichia coli, followed by Klebsiella, Proteus, and the enterococcus. Group B Streptococcus and Staphylococcus saprophyticus have also been noted as important urinary pathogens (Sweet \& Gibbs, 2009).

a. Urine dipstick for nitrites and leukocyte esterase is a less expensive way to screen for UTI after the initial UA and urine culture. The urine dipstick alone is not sensitive enough to be used for a screening test for ASB. Nitrites are by-products of bacterial growth and are frequently present when there is a UTI. However, for best results, the urine must be in the bladder for 4 hours or longer. Gram-negative rods, such as $E$. coli, are more likely to produce a positive test. Leukocyte esterase may not be as useful to the clinician as vaginal contamination readily causes positive leukocyte esterase urine. Those patients at risk for a UTI should have a UA and culture repeated at least once or once in each trimester. 
2. In the absence of hypertension, routine urine screening for glucosuria

and proteinuria beyond the first prenatal visit has not been found to be useful in identifying patients at risk for gestational diabetes or preeclampsia (Alto, 2005, 2007). A trace amount of protein may be found in a urine specimen during normal pregnancy. In addition, healthy pregnant individuals may manifest glucosuria without abnormal plasma glucose levels.

\section{STI SCREENING: CHLAMYDIA AND GONORRHEA}

1. Nucleic acid amplification testing (NAAT) is considered the gold standard for the diagnosis of genital Chlamydia trachomatis infections. FDAapproved kits are available for endocervical, urine, urethral specimens, and liquid-based Pap test specimens. The NAAT method detects the genetic material of the bacteria, living or dead, and therefore is not used to determine treatment effectiveness. However, the sensitivities reported for NAATs range from approximately $90 \%$ to $97 \%$; the specificities are more than $99 \%$ (Williamson \& Snyder, 2014).

2. Test of cure is not routinely required. However, if the patient had gastrointestinal (GI) side effects as a result of antimicrobial therapy, compliance may have been an issue.

\section{E. TB SKIN TESTING (PROTEIN PURIFIED DERIVATIVE)}

1. TB continues to be a public health problem. Untreated TB represents a greater hazard to a pregnant individual and fetus than does its treatment. The tuberculin skin test (TST) is considered both valid and safe to use throughout pregnancy. The TB blood test is safe to use during pregnancy but has not been evaluated for diagnosing Mycobacterium tuberculosis infection during pregnancy. Other tests are needed to show whether a person has TB.

2. Testing for TB in Bacille Calmette-Guérin (BCG)-vaccinated persons:

a. The TST and blood tests to detect TB infection are not contraindicated for persons who have been vaccinated with BCG.

b. TST: BCG vaccination may cause a false-positive reaction to the TST, which may complicate decisions about prescribing treatment. The presence or size of a TST reaction in persons who have been vaccinated with BCG does not predict whether BCG will provide any protection against TB disease. Furthermore, the size of a TST reaction in a BCG-vaccinated person is not a factor in determining whether the reaction is caused by latent TB infection (LTBI) or the prior BCG vaccination. BCG vaccination should not be given during pregnancy. Even though no harmful effects of BCG vaccination on the fetus have been observed, further studies are needed to prove its safety.

c. TB blood tests: Blood tests to detect TB infection, unlike the TST, are not affected by prior BCG vaccination and are less likely to give a falsepositive result.

3. Persons with no known risk factors for TB may be considered for treatment of LTBI if their reaction to the tuberculin test is at least $15 \mathrm{~mm}$ of induration or they have a positive result using a TB blood test. Targeted skin testing programs should only be conducted among high-risk groups. All testing activities should be accompanied by a plan for follow-up care for persons with TB infection or disease.

4. Treatment of pregnant persons should be initiated whenever the probability of TB is moderate to high. Infants born to mothers with untreated TB may be of lower birth weight than those born to mothers without TB, and, in rare circumstances, the infant may be born with TB. Although the drugs used 
in the initial treatment regimen for TB cross the placenta, they do not appear to have harmful effects on the fetus.

\section{F. OTHER TESTS}

1. Hgb electrophoresis: Sickle cell anemia, thalassemia major, and $\mathrm{Hgb} \mathrm{C}$ are common autosomal recessive hemoglobinopathies. Like other autosomal recessive disorders, a fetus is at risk for sickle cell anemia and thalassemia major if both parents are carriers of the trait (see Chapter 2). However, a milder form of anemia may exist if the individual has one normal gene and one gene for the trait. There may be a combination of traits as well. An individual has a $25 \%$ chance of inheriting sickle-thalassemia or Hgb SCD if one parent carries the sickle cell trait and the other parent carries the trait for either thalassemia or Hgb C. Sickle-thalassemia can be as severe as sickle cell anemia. In Hgb SCD, there is less marked destruction of RBCs and anemia; hence, the disorder is less severe clinically (Williamson \& Snyder, 2014). A quick screening test is available to detect sickle cell traits, but it does not differentiate between those who have the disease or the trait. An Hgb electrophoresis provides more detailed information that includes the thalassemias and other hemoglobinopathies. These recessively inherited conditions occur in the United States primarily in families of Asian, Middle Eastern, African, and Mediterranean descent. Pregnant individuals of African descent are routinely screened for these disorders as the prevalence rate for sickle cell trait in these patients is $8 \%$ to $12 \%$ in the United States.

2. The TORCH acronym is well known in the fields of neonatal/perinatal nursing. Infections acquired in utero or during the birthing process may lead to abnormal growth, developmental anomalies, or multiple clinical and laboratory abnormalities. The $\mathrm{O}$ for Other has been expanded to include not only syphilis but also other causes of in utero infection. TORCH: (T) toxoplasmosis, caused by the protozoan parasite Toxoplasma gondii, can lead to an increased risk of vision loss, intellectual disability, deafness, seizures, and muscle spasticity; $(\mathrm{O})$ other organisms (parvovirus B19, HIV, Epstein-Barr virus, zika, varicella-zoster virus, syphilis, and enteroviruses), ( $R$ ) rubella, now rare in the United States due to immunization programs, can lead to an increased risk of deafness, cataracts, cardiac malformations, neurologic disorders, and endocrine sequelae; (C) cytomegalovirus, is common worldwide and is the leading cause of sensorineural hearing loss and other neurodevelopmental disabilities including cerebral palsy, intellectual disability, vision impairment, and seizures; and (H) herpes simplex virus (HSV), with most cases being acquired during the birthing process. HSV infections in newborns may be localized to the skin, eyes, mouth, central nervous system, or disseminated involving multiple organs. Gestational age at the time of any of the TORCH infections greatly influences the effect on the fetus.

3. Vitamin D deficiency: Although recent evidence suggests that vitamin $\mathrm{D}$ deficiency is fairly common during pregnancy, there is not enough evidence to support universal screening. An optimal serum level for pregnancy has not been established, but for those individuals thought to be deficient $(<32 \mathrm{ng} / \mathrm{mL})$, vitamin D supplementation of 1,000 to 2,000 IU per day is safe (ACOG, 2015).

\section{G. ULTRASOUND EXAMINATION IN THE FIRST TRIMESTER}

1. A sonographic examination can be of benefit in many circumstances in the first trimester of pregnancy, including but not limited to the 
following indications (according to the American Institute of Ultrasound in Medicine):

a. To confirm the presence of an intrauterine pregnancy

b. To evaluate a suspected ectopic pregnancy

c. To define the cause of vaginal bleeding

d. To evaluate pelvic pain

e. To estimate gestational (menstrual) age

f. To diagnose or evaluate multiple gestations

g. To confirm cardiac activity

h. As an adjunct to chorionic villus sampling, embryo transfer, and localization and removal of an intrauterine device

i. To assess for certain fetal anomalies, such as anencephaly, in highrisk patients

j. To evaluate maternal pelvic masses and/or uterine abnormalities

k. To measure nuchal translucency when part of a screening program for fetal aneuploidy

1. To evaluate a suspected hydatidiform mole

2. Limited examination may be performed to evaluate interval growth, estimate amniotic fluid volume, evaluate the cervix, and assess the presence of cardiac activity

3. Components of the basic ultrasound examination include the following:

a. Intrauterine pregnancy

b. The uterus, including the cervix, and adnexa should be evaluated for the presence of a gestational sac. If a gestational sac is seen, its location should be documented. The gestational sac should be evaluated for the presence or absence of a yolk sac or embryo, and the crown-rump length should be recorded, when possible. Embryonic/fetal anatomy is appropriate for the first trimester.

c. Fetal number

d. Cardiac activity

e. The uterus, including the cervix, adnexal structures, and cul-de-sac, should be evaluated

f. Free fluid

g. If possible, the appearance of the nuchal region should be assessed as part of a first-trimester scan when a live fetus is present

4. Order of appearance of structures

a. Gestational sac: 4 to 5 weeks

b. Yolk sac: 5 to 6 weeks

c. Fetal pole: 6 to 7 weeks

d. Cardiac activity: 6 to 7 weeks

\section{Common Discomforts in the First Trimester}

\section{A. NAUSEA AND VOMITING}

1. Definition: Among the most common complaints, nausea and vomiting occur in $50 \%$ to $80 \%$ of pregnant individuals. The problem can have a major impact on the quality of life of the pregnant individual, causing missed workdays and affecting job performance. The term "morning sickness," although common, is a misnomer as nausea can occur anytime. The cause is unknown, and there is no evidence to support the notion that psychological factors play a role. Influencing factors include high levels of circulating steroids (estrogen and HCG), slowed peristalsis of the GI tract due to progesterone, pressure from the enlarging uterus, gastric overloading, low blood sugar, and changes in carbohydrate metabolism. 
2. History

a. Sensation of nausea

b. Loss of appetite

c. Aversion to certain types of foods

d. Aversion to the smell or sight of food

e. Vomiting

f. Additional information to consider

i. The patient is between 4 and 16 weeks of pregnancy

ii. Symptoms occur with fatigue

iii. Absence of fever, diarrhea, and abdominal pain

3. Physical examination

a. Unremarkable

i. Vital signs are within normal limits

ii. Weight variable depending on the severity of the symptoms

iii. No evidence of dehydration in mucous membranes, skin turgor, or urine-specific gravity

iv. Abdominal examination is negative for organomegaly, pain, tenderness, or guarding

v. Fetal heart tone auscultation is appropriate for gestation

vi. Fundal height is appropriate for gestation

4. Laboratory examination

a. Urine negative or positive for ketones; negative or trace proteinuria

b. CBC, electrolytes may be done for patients who are severely nauseated but will show absence of severe hemoconcentration, normal WBC counts, and absence of acidosis

5. Differential diagnosis

a. Hyperemesis gravidarum

b. Multiple gestation

c. Hydatidiform molar pregnancy

d. Infectious process (gastric influenza, appendicitis, pancreatitis, intestinal parasites, UTI/pyelonephritis, and hepatitis)

e. Drug or alcohol effect

f. Gall bladder disease

g. Hyperthyroidism

h. Migraine headache

i. Food poisoning

j. Bulimia

k. Diabetic ketosis

1. Malaria

6. Treatment

a. Reassurance that the condition will end

b. Small frequent meals

c. Avoid foods with strong odors or tastes (individual preferences/dislikes may change in pregnancy)

d. Avoid low blood sugar levels; eat high-protein foods frequently; decrease fluid intake with and between meals, or separate fluids and solids (patterned intake)

e. Avoid high-fat foods

f. Acupressure wrist bands: Low-tech varieties are available (elastic bands with ball that is placed two fingerbreadths below the bend of the wrist over the tendon on the inner aspect of the forearm, worn bilaterally) as an alternative to the more expensive and higher tech ReliefBand that is worn on one arm and has a transcutaneous electric nerve stimulator unit, which is available at Reliefband.com 
g. Ondansetron ODT (Zofran ODT) 4 to $8 \mathrm{mg} / \mathrm{d}$ : Data are limited and unclear as to the association with birth defects. There is no clear benefit for using this drug over other agents (Kennedy, 2016). Recent studies analyzed data from more than 88,000 pregnancies in which pregnant individuals took ondansetron during the first trimester to examine the risk of cardiac malformations or oral clefts. The teams report no increased risk of cardiac malformations and a very small increased risk of oral clefts in studies published online in JAMA (Huybrechts et al., 2018, 2020).

h. Possibly beneficial: A diet rich in $B$ complex vitamins, vitamin $B_{6}$ supplements such as $\mathrm{B}_{6} 25$ to $50 \mathrm{mg}$ two to three times a day. Unisom (doxylamine) $25 \mathrm{mg}$ at bedtime or twice a day (Briggs et al., 2011).

i. Stop smoking

j. Suck on hard candy (sour or sweet), such as Atomic Fireballs (cinnamon candy)

k. Eat popcorn or melba toast before rising out of bed and then eat a high-protein breakfast

1. Combine sweet and salty foods (potato chips and lemonade)

m. Brush teeth more often; rinse mouth frequently

n. Reduce fat, fried foods, and spices in diet

o. Good posture and nausea-preventing exercise

p. Stop chewing gum

q. Herbal teas: The FDA does not regulate these teas and considers them to be dietary supplements. Safe teas include raspberry leaf tea, ginger, and peppermint. Avoid black or blue cohosh, kava, and St. John's wort as these stimulate uterine activity.

r. Consider that prenatal vitamins may be contributing to the nausea. Have the patient use the "gummy" or "chewable" variety, as these are not upsetting to the stomach for most patients. Doses can be divided.

7. Warning signs/complications

a. Inability to retain food for 24 hours or more; any weight loss, rule out hyperemesis gravidarum

b. Ketone bodies in urine suggest severe/prolonged vomiting or prolonged fasting

c. Dizziness, dry mucous membranes, decreased urination, and other signs of dehydration

d. Persistent nausea and vomiting after first trimester; rule out hydatidiform mole and/or pregnancy-induced hypertension

e. If abnormal vital signs, abdominal pain or tenderness, and/or diarrhea are present, rule out infections, pancreatitis, GI conditions such as intestinal obstruction, appendicitis, cholelithiasis, cholecystitis, hepatitis, pyelonephritis, and food poisoning

f. If there is a lack of heart tones, uterus greater than estimated gestational age, persistent nausea and vomiting, and/or abnormal vaginal bleeding, rule out hydatidiform mole

8. Consultation/referral

a. If no response to treatment

b. If complications develop (see previous item Warning Signs)

9. Follow-up

a. Contact provider if unable to retain fluids for 12 hours or more

b. Continued weight loss: recheck weight weekly until symptoms subside

c. Check urine ketones and signs of dehydration until symptoms subside

d. If symptoms respond to treatment, check at routine intervals, that is, in 4 weeks 
1. Definition: An abrupt, usually brief loss of consciousness, generally associated with an alteration of normal blood circulation

2. History: The patient complains of slight dizziness, swirling, or a floating sensation and a decrease in the ability to hear or focus attention; accompanied by prolonged standing or being in a warm, crowded room

3. Physical examination: Unremarkable, although supine hypotension can be replicated by placing the patient in a supine position (usually third-trimester phenomenon)

4. Laboratory examination: $\mathrm{CBC}$, random blood sugar only if there is reason to suspect gestational diabetes or a neurologic or cardiovascular problem

5. Differential diagnosis

a. Heat-causing dilation of blood vessels, which lowers blood pressure

b. Hyperventilation caused by progesterone acting on the respiratory center of the brain

c. Hypoglycemia caused by a change in carbohydrate metabolism

d. Supine hypotension (when supine pressure of gravid uterus on vena cava decreases blood flow to the heart)

e. Orthostatic hypotension (late pregnancy venous stasis in lower extremities decreases the amount of blood filling the heart when moving from sitting/lying to standing)

6. Treatment: Advise patient regarding the following:
a. Moderate exercise
b. Deep breathing
c. Move slowly and avoid standing still for a prolonged period
d. Avoid low blood sugar levels by eating five to six small meals per day
e. Avoid warm crowded areas
f. If standing, lie down or sit with head in lap
g. Avoid hot showers or baths
h. Avoid supine position in the third trimester, use a side-lying position
i. Wear anti-embolism compression (TED [thrombo-embolic deter- rent]) stockings

7. Consultation/referral

a. Refer or consult with a physician if cardiovascular or neurologic condition suspected

\section{FATIGUE}

1. Definition: Marked fatigue, out of proportion to the patient's normal pattern

2. Etiology: Thought to be caused by the sleep-inducing effects of progesterone. This is so common that it is one of the presumptive signs of pregnancy

3. History: Reports needing frequent periods of rest, which is different from the usual pattern
a. Details about the fatigue's duration (recent, prolonged, or chronic)
b. Onset (sudden or progressive)
c. Recovery period (short or long)
d. Type (physical or mental fatigue)
e. Patient's usual level of physical activity (sedentary or active)
f. Symptoms began with the pregnancy

4. Physical examination: unremarkable

5. Laboratory examination: usual prenatal panel

6. Differential diagnosis

7. Fatigue is very broad but could include: 
a. Iron-deficiency anemia

b. Mononucleosis

c. Depression

d. Chronic fatigue syndrome

e. Sleep disorder

f. Medication use

8. Treatment

a. Reassurance that the condition usually resolves by 16 weeks gestation

b. Plan rest periods, including going to sleep earlier in the evening

c. Partner should be encouraged to assume more responsibilities, so the patient can rest

\section{First-Trimester Education/Anticipatory Guidance}

A. NUTRITION, FOOD SAFETY, AND WEIGHT GAIN IN PREGNANCY

1. Periconceptional nutrition is vital to the critical period (first 12 weeks) of organ development. Maintaining optimal nutrition during this period can be a challenge, especially when the patient is nauseated. Simple instructions include advising eating small frequent meals that include all food groups: "Put a lot of color on your plate" and to stay hydrated. Updated and patient-friendly information is available at www.ChooseMyPlate.gov. The current dietary recommendations developed by the IOM (2009a) are as follows:

a. Protein intake is essential, and many women do not take in an adequate amount. The recommended amount is $70 \mathrm{~g} / \mathrm{d}(1.1 \mathrm{~g} / \mathrm{kg} / \mathrm{d})$ or three to four servings per day. Typical sources include dairy, beans, nuts, legumes, meat, poultry, and fish.

b. Omega-3 fatty acids: Optimal fetal neurodevelopment is dependent on many essential nutrients, including docosahexaenoic acid (DHA) and eicosapentaenoic acid (EPA), which can be obtained only from dietary sources. Essential fatty acids are lipids that cannot be synthesized within the body. The standard Western diet is severely deficient in essential fatty acids because the best sources are cold-water fish, such as salmon, tuna, sardines, anchovies, and herring. Therefore, supplementation with $300 \mathrm{mg}$ of DHA daily is recommended.

i. Omega-3 dietary deficiency is compounded by the fact that pregnant individuals become depleted in omega-3s when the fetus uses omega-3s for its nervous system development. Omega-3s are also used after birth to make breast milk. With each subsequent pregnancy, mothers are further depleted.

ii. Adding omega-3s to the diet of pregnant individuals has a positive effect on the visual and cognitive development of the baby as well as possibly reducing the risk of allergies in infants. Increased intake of EPA and DHA has been shown to reduce the risk of preterm labor and delivery in at-risk populations, may lower the risk of preeclampsia, and may increase birth weight. Omega-3 deficiency may also increase the risk for depression.

iii. Quality fish oil (labeled U.S. Pharmocopeia [USP]) is safe to take during pregnancy. Fresh fish (that is eaten) can often contain environmental toxins like mercury that accumulate during the fish's life span. These toxins can be virtually eliminated during the manufacture and processing of fish oil, with the use of high-quality raw materials and an advanced refining process. 
c. Iron: Increase iron intake from 15 to $30 \mathrm{~g} / \mathrm{d}$

d. Folic acid: Increased folate consumption from 400 to $800 \mathrm{mcg} / \mathrm{d}$

i. There are certain special circumstances that may affect these recommendations. For example, if there is a history of a child with a neural tube defect, the folic acid recommendation in a subsequent pregnancy is increased to $4 \mathrm{mg}$ rather than 0.4 to $0.8 \mathrm{mg} / \mathrm{d}$

e. Calcium: The recommended amount of calcium for women aged 19 to 50 , pregnant or not, is $1,000 \mathrm{mg} / \mathrm{d}$; for adolescents up to age 18 , it is $1,300 \mathrm{mg}$ daily

f. Vitamin D: $600 \mathrm{IU} / \mathrm{d}$

g. Add 340 additional calories per day in the second trimester and 452 calories per day in the third trimester

h. Fiber: $28 \mathrm{~g} / \mathrm{d}$

i. Water intake: Water is important not only to prevent dehydration, but recent research suggests the importance of sufficient water consumption (mean consumption is about four and a half 8-oz glasses/day) during early pregnancy to decrease the risk of birth defects, including neural tube defects, cleft lip, gastroschisis, and congenital heart defects (Alman et al., 2017).

2. Caffeine use in pregnancy: Data remains inconsistent, with controversy regarding caffeine safety and consumption during pregnancy (National Academies of Sciences, Engineering, and Medicine, 2020). Caffeine metabolism and pharmacokinetics are influenced by many factors, including genetic variability (Hale, 2019; Langer, 2018; Nehlig \& Alexander, 2018). Polymorphisms of the CYP1A2 enzyme determine whether caffeine will be metabolized rapidly or slowly by an individual (Langer, 2018).

\section{Relevant to the NP:}

a. Consumption of up to $400 \mathrm{mg}$ caffeine/d in healthy adults and 300 $\mathrm{mg}$ caffeine/d in healthy pregnant women is generally recognized as safe (Hale, 2019; Rosenfeld et al., 2014; Wikoff et al., 2017).

b. Pregnant women, preterm, and newborn infants metabolize caffeine more slowly; therefore, reduced maternal caffeine intake to $<200 \mathrm{mg}$ is often recommended (LactMed®).

c. Smoking stimulates caffeine clearance and oral contraceptives decrease clearance (Langer, 2018, Nehlig \& Alexander, 2018).

d. There is no requirement by the FDA to list the amount of caffeine on product.

\section{Regulation, Labeling, and Safety of Caffeinated Products:}

Caffeine is naturally found in coffee, tea, chocolate, and may be an additive to medications, foods, beverages, weight-loss products, and cosmetics (IOM, 2014; National Academies of Sciences, Engineering, and Medicine, 2020). The market of caffeinated products is proliferating, and patterns of consumer use are not well understood (National Academies of Sciences, Engineering, and Medicine, 2020). Estimating caffeine exposure in these products is challenging (Kallmyer, 2019; Leviton, 2018). Federal regulations surrounding product labeling are complex. The USFDA regulates caffeine levels in foods and dietary supplements; however, there is no requirement to list the amount of caffeine on product labels (Foster, 2017; USFDA \& Center for Food Safety and Applied Nutrition, 2018). American Beverage Association (ABA) member companies-representing $95 \%$ of energy drinks sold in the 
United States-comply with the ABA Guidance for Responsible

Labeling and Marketing of Energy Drinks and voluntarily include cautionary labels advising against use by children, pregnant/lactating women, and individuals sensitive to caffeine (ABA, 2020; Rosenfeld et al., 2014). Caffeine content varies by product and serving size. The Center for Science in the Public Interest (2021) provides a caffeine chart containing approximate content in foods and beverages:

i. A 20-ounce coffee may contain up to $398 \mathrm{mg}$

ii. A 16-ounce iced or regular tea may contain up $98 \mathrm{mg}$

iii. A 16-ounce energy drink may contain up to $300 \mathrm{mg}$ and indeterminate amounts of herbal stimulants

iv. Varied sizes of caffeinated shakes and waters may contain from 30 to100 mg

v. Assorted sizes of chocolate candy/drinks may contain from 2 to $600 \mathrm{mg}$

vi. OTC weight-loss supplements and medications may contain from 64 to $300 \mathrm{mg}$

3. Weight gain in pregnancy: Approximately $60 \%$ of American pregnant individuals do not gain the appropriate amount of weight during pregnancy, with the majority gaining too much, especially those with a high prepregnancy BMI (Olson, 2008). The U.S. Department of Agriculture created an interactive web-based site, which is now known as "ChooseMyPlate." The website provides food intake and physical activity recommendations for persons age 2 and older, replacing healthy foods for unhealthful, diet tracking, menu planning, nutrition information, and personalized advice. The strategies are easy to understand for the lay public. The information should be used to complement and not substitute for prenatal education (Shieh \& Carter, 2011). The NP is encouraged to explore the website for use with preconception, prenatal, and lactating individuals (www.choosemyplate.gov) (Table 3.3).

\section{TABLE 3.3 RECOMMENDATIONS FOR WEIGHT GAIN DURING PREGNANCY}

\begin{tabular}{|l|l|l|}
\hline $\begin{array}{l}\text { PREPREGNANT } \\
\text { STATUS }\end{array}$ & BMI & WEIGHT GAIN (LB/KG) \\
\hline Singleton pregnancy \\
\hline Underweight & $<18.5$ & $28-40 \mathrm{lb}(12.7-18.2 \mathrm{~kg})$ \\
\hline Normal weight & $18.5-24.9$ & $25-35 \mathrm{lb}(1 \mathrm{I} .4-15.9 \mathrm{~kg})$ \\
\hline Overweight & $25.0-29.9$ & $15-25 \mathrm{lb}(7.0-1 \mathrm{I} .5 \mathrm{~kg})$ \\
\hline Obese & $>30$ & $\mathrm{II}-20 \mathrm{lb}(5.0-9 \mathrm{~kg})$ \\
\hline Twin pregnancy & \multicolumn{3}{|l|}{} \\
\hline Underweight & $<18.5$ & No recommendation due to insufficient data \\
\hline Normal weight & $18.5-24.9$ & $37-54 \mathrm{lb}(16.8-24.5 \mathrm{~kg})$ \\
\hline Overweight & $25.0-29.9$ & $3 \mathrm{I}-50 \mathrm{lb}(14.1-22.7 \mathrm{~kg})$ \\
\hline Obese & $>30$ & $\mathrm{II}-20 \mathrm{lb}(\mathrm{II} .4-19.1 \mathrm{~kg})$ \\
\hline
\end{tabular}

BMI, body mass index.

Source: Adapted from www.iom.edu/Reports/2009b/Weight-Gain-During-Pregnancy-Reexamining the-Guidelines. aspx. 
B. VITAMINS, HERBAL SUPPLEMENTS, AND MEDICATION (PRESCRIPTION AND OTC)

1. Prenatal vitamin supplements vary in composition. Generally, the vitamin should contain
a. $400 \mathrm{mcg}$ of folic acid
b. 400 IU of vitamin D
c. 200 to $300 \mathrm{mg}$ of calcium
d. $70 \mathrm{mg}$ of vitamin $\mathrm{C}$
e. $3 \mathrm{mg}$ of thiamine
f. $2 \mathrm{mg}$ of riboflavin
g. $20 \mathrm{mg}$ of niacin
h. $6 \mathrm{mcg}$ of vitamin $B_{12}$
i. $10 \mathrm{mg}$ of vitamin $\mathrm{E}$
j. $15 \mathrm{mg}$ of zinc
k. $17 \mathrm{mg}$ of iron

1. Fish oil can be added as a separate supplement or is added to some brands for an added cost. Some patients become nauseated from the prenatal vitamin. Using a children's chewable or "gummy" or prenatal "gummy" allows for dividing the dose and is usually well tolerated.

2. Anemia: In addition to taking an iron supplement, patients who are anemic should be counseled to consume iron-rich foods such as (heme source) spinach, beef, beef or chicken liver, clams or mollusks, oysters, cooked turkey, and (nonheme source) breakfast cereals enriched with iron, beans, dried apricots, baked potato, enriched egg noodles, tofu, pumpkin, sesame, or squash seeds (see Chapter 10).

3. Herbal supplements: There is a large variety of herbal supplements being marketed to pregnant individuals. Many $(1 \%-87 \%)$ pregnant individuals use complementary and alternative medicine, but this practice is not well studied. Common modalities include massage, vitamin and mineral supplements, herbal medicine, relaxation therapies, and aromatherapy. Therefore, an open discussion should be initiated with the patient concerning alternative therapies. Patients should be advised to consult their NP or nurse midwife before ingesting or using these supplements. The following substances have the potential to harm during pregnancy when used in a concentrated formulation (not as a spice in cooking).

a. Oral supplements: arbor vitae, beth root, black cohosh, blue cohosh, cascara, chaste tree berry, Chinese angelica (dong quai), cinchona, cotton root bark, feverfew, ginseng, goldenseal, juniper, kava kava, licorice, meadow saffron, pennyroyal, poke root, rue, sage, St. John's wort, senna, slippery root, tansy, white peony, wormwood, yarrow, yellow dock, and vitamin A (large doses can cause birth defects)

b. Aromatherapy essential oils: calamus, mugwort, pennyroyal, sage, wintergreen, basil, hyssop, myrrh, marjoram, and thyme

c. Further resource: www.pregnancy.org/article/herbs-avoid-duringpregnancy

4. Food safety: For example, norovirus, which causes acute gastroenteritis; Salmonella; listeriosis; E. coli; hepatitis A. Pregnant individuals have increased susceptibility to listeriosis. Listeriosis can lead to spontaneous abortion, preterm delivery, stillbirth, or serious infection in infants. The FDA provides advice on food safety (www.fda.gov/food/resourcesforyou/healtheducato rs/ucm081785.htm).

5. The March of Dimes also provides patient-friendly materials at www.m archofdimes.com/pregnancy/nutrition_foodsafety.html. To reduce the risk of food-borne illness, it is important for the pregnant individual to: 
a. Practice good personal hygiene (handwashing and care of kitchen utensils, cookware, and surfaces)

b. Consume meats, fish, poultry, and eggs that are fully cooked

c. Avoid unpasteurized dairy or juice, fruit/vegetable products

d. Wash fresh fruits and vegetables prior to eating

e. Avoid raw sprouts (alfalfa, clover, radish, and mung bean)

f. Avoid listeriosis by refraining from unheated processed/deli meats and hot dogs, soft cheeses like feta or brie, smoked seafood, meat spreads, and pâté

g. Avoid certain types of seafood: king mackerel, swordfish, tilefish, and shark. The FDA recommends that pregnant individuals eat up to 12 oz a week (two average meals) of a variety of fish and shellfish that are lower in mercury, such as canned light tuna, salmon, pollock, and catfish. No more than $6 \mathrm{oz}$ a week should be consumed of canned "solid white" or albacore tuna or if the fish in question is caught privately in local waters and health authorities are unable to provide any relevant safety information.

\section{EXERCISE}

1. Preexercise medical screening: A clinical evaluation of the pregnant patient should be conducted prior to prescribing an exercise regimen. At least 30 minutes of moderate exercise on most days is a reasonable activity level for most pregnant individuals. The factors to include in screening are as follows:

a. Age

b. General physical condition

c. Exercise history

d. Risk factors for coronary artery disease

e. Musculoskeletal risks

f. Medication use

g. History of pulmonary disease

h. Anticipated type of exercise

i. Handicaps or disability

j. Current or previous obstetrical history

2. Some activities carry more risk in pregnancy than others, for example, contact sports or skiing. Scuba diving is to be avoided completely. Pregnant individuals who pursue activities that increase the risk of falls or contact (soccer, basketball) or joint stress (jogging) should be cautioned. Many pregnant individuals will benefit from a walking regimen, especially those who were not active prior to pregnancy. Activities that promote musculoskeletal fitness include strength training, resistance training, and flexibility exercises. Water exercise appears to have benefits that include the reduction of edema, thermoregulation, and buoyancy, which reduces the risks of joint injuries during pregnancy. Pregnancy should not be thought of as a time to "get in shape." Patients who exercised before pregnancy should be able to continue to do so as long as the pregnancy is healthy and uncomplicated. The CDC recommends that healthy pregnant and postpartum individuals get at least 150 minutes of moderate-intensity aerobic activity per week, such as brisk walking and should be cautioned to remain hydrated.

3. Pregnant individuals with gestational diabetes who exercise may improve their glucose control. Obese pregnant individuals who exercise reduce the risk of developing gestational diabetes. Pregnant patients who exercise are at lower risk for developing preeclampsia. 
Absolute Contraindications to Aerobic Exercise During Pregnancy

a. Hemodynamically significant heart disease

b. Restrictive lung disease

c. Incompetent cervix/cerclage

d. Multiple gestation at risk for premature labor

e. Persistent second-or third-trimester bleeding

f. Placenta previa after 26 weeks of gestation

g. Premature labor during the current pregnancy

h. Ruptured membranes

i. Preeclampsia/pregnancy-induced hypertension Signals to Stop Exercising While Pregnant

i. Vaginal bleeding

ii. Dyspnea prior to exertion

iii. Fatigue

iv. Dizziness

v. Headache

vi. Chest pain

vii. Muscle weakness

viii. Calf pain or swelling (need to rule out thrombophlebitis)

ix. Preterm labor

x. Decreased fetal movement

xi. Amniotic fluid leakage

xii. Pain in back, hips, or pubic bone

xiii. Difficulty walking

xiv. Significant swelling in feet or legs

D. SEXUAL INTERCOURSE

(www.marchofdimes.com/pregnancy/physicalactivity_sex.html)

\section{E. ITEMS TO AVOID}

1. Hot tubs and sauna

2. Hair dyes (unless vegetable based)

3. Tobacco

4. Alcohol

5. Illicit drugs

6. Workplace/occupational hazards

\section{F. DISCOMFORTS TO EXPECT}

1. Nausea

2. Fatigue

3. Frequent urination

4. Breast tenderness

\section{G. TRAVEL DURING PREGNANCY}

1. Air travel: Long-haul air travel is associated with an increased risk of venous thrombosis. Advise the patient to wear correctly fitted compression stockings as this is effective at reducing the risk.

2. Car travel: Pregnant individuals should be informed about the correct use of seat belts (i.e., three-point seatbelts "above and below the bump, not over it").

3. Traveling abroad: If a pregnant individual is planning to travel abroad, she should be informed regarding infectious disease prevalence, such as Covid-19, Zika or Chagas disease, vaccinations, airline policies, and travel insurance. 
4. See www.acog.org/womens-health/faqs/travel-during-pregnancy for

additional information on travel recommendations during pregnancy.

\section{H. DANGER SIGNS IN PREGNANCY}

1. Vaginal bleeding

2. Nausea and excessive vomiting that lasts more than 24 hours

3. Fever (more than $100.4^{\circ} \mathrm{F}$ )

4. Dizziness; sudden and extreme and associated with pelvic or uterine pain

5. Preterm labor signs and symptoms (see Chapter 18)

6. Leaking of fluid from the vagina

7. Preeclampsia symptoms:

a. Rapid weight gain

b. Headaches

c. Visual disturbances, vomiting, epigastric pain, irritability, scanty urine output (see Chapter 16)

8. Decreased fetal activity (see Appendix A and Chapter 6)

9. Symptoms of a UTI:
a. Dysuria
b. Severe backache
c. Fever (see Chapter 12)

\section{INDICATIONS FOR CONSULTATION/REFERRAL}

1. A pregnant individual who by medical/family history is considered high risk
a. Maternal cardiac disease
b. Maternal hypertensive disease
c. Diabetes mellitus and glucose intolerance of pregnancy
d. Maternal pulmonary disease (asthma not controlled)
e. Maternal renal disease
f. Maternal collagen disease
g. Hemoglobinopathies
h. Anemia
i. Psychiatric illness
j. Rh sensitization or other isoimmunization
k. Habitual abortion (three or more)
1. Previous second-or third-trimester pregnancy loss
m. Known substance abuse
n. Serious maternal infectious disease (e.g., HIV, hepatitis, TB)
o. Prior early preterm delivery (before 34 weeks)
p. Prior infant with a genetic abnormality or major congenital anomaly

2. Abnormal findings on the physical or ultrasonic examination
a. Multiple gestation
b. No fetal heart activity
c. Ectopic pregnancy
d. Breast mass
e. Short cervix ( $<25 \mathrm{~mm})$

3. Abnormal laboratory findings

a. Positive HIV test result

b. Abnormal Pap smear with higher atypical squamous cells of undetermined significance (ASCUS)

c. Anemia $(\mathrm{Hgb}<10 \mathrm{mg} / \mathrm{dL})$

d. Positive screen for significant antibody 
4. The following may be indications for a social service consultation/ referral
a. Financial problems
b. History of abuse (either by an intimate partner or as a child)
c. Family/marital issues
d. History of psychiatric/mental illness
e. Need for community resources such as food stamps, WIC; placement for adoption

\section{J. FOLLOW-UP CARE}

1. As indicated by gestation

a. Every 4 weeks until 28 weeks gestation, every 2 weeks until 36 weeks, every week until delivery

\section{Special Considerations}

\section{A. INTIMATE PARTNER VIOLENCE}

1. IPV is defined broadly as including emotional degradation, threats, and intimidation, as well as a physical or sexual assault from an intimate partner (Ulrich et al., 2006). IPV often starts, or if already occurring, may increase during pregnancy. The incidence is estimated to occur in $1 \%$ to $20 \%$ of pregnancies, depending on the way IPV is assessed. There is a threefold higher risk for IPV in unintended pregnancy versus intended pregnancy. Although women of all socioeconomic status (SES) have suffered IPV, women of lower SES have an increased risk in both pregnant and nonpregnant populations. Younger women, unmarried, separated or divorced, and those from minority groups are also at an increased risk for IPV. There is also an increased risk if the couple is cohabitating rather than married. Married women who live apart from their spouses are also more likely to be victims of rape, assault, and/or stalking (Tjaden \& Thoennies, 2000).

Adverse pregnancy outcomes are many and varied. Pregnant individuals who are abused (physical, sexual, or emotional) are more likely to deliver preterm and/or low-birth-weight babies, have a cesarean delivery, be hospitalized for premature labor, pyelonephritis, and trauma as a result of blows to the abdomen or falling. These patients also have a threefold higher risk for becoming a victim of attempted/completed homicide. Total healthcare costs from IPV run into the billions in the United States.

a. Risk profile: There is no single profile of the individual who suffers abuse (see nicic.gov/intimate-partner-violence-risk-assessment-tools-re view). Presenting patterns may include the following:

i. Unwanted pregnancy

ii. Late entry into prenatal care, missed appointments

iii. Substance use or abuse

iv. Poor weight gain and nutrition

v. Multiple, repeated somatic complaints (AAP \& ACOG, 2013)

2. Screening tools: Given the high rates of IPV in the perinatal period and the associated negative health outcomes, NPs should routinely screen for IPV; without such screening, few IPV cases are likely to be detected, and patients cannot be appropriately referred to resources. Assessing for IPV should be performed in different ways (written and verbally) using culturally appropriate language. Assessment strategies and interventions must be appropriate to age, culture, and ethnicity as well as specific to the stage in an abusive relationship. Abuse in a relationship is not a "discrete" event but rather a process. Some patients may resist the label of "abuse" but will acknowledge that there 
are problems in their relationships. This may be culturally mediated as the behavior is viewed as "normal" for the environment in which the patient lives. Families and friends do not intervene even with knowledge of the abusive activity. Coping strategies that the patient uses can be elicited. How the patient interprets the situation may make the individual more vulnerable to depression as well as an escalation of violence and danger.

Six screening instruments designed to detect current or recent IPV demonstrated high diagnostic accuracy (Nelson et al., 2012).

a. Hurt, Insult, Threaten, and Scream (HITS) instrument: Both English and Spanish versions of the four-item HITS instrument have sensitivity and specificity greater than $85 \%$. HITS consists of the following four screening questions:

i. "Over the past 12 months, how often did your partner: physically hurt you; insult you or talk down to you; threaten you with physical harm; and scream or curse at you?" Patients responded to each of these items with a five-point frequency format: never, rarely, sometimes, fairly often, and frequently. Score values can range from a minimum of 4 to a maximum of 20 (Sherin et al., 1998).

b. The Ongoing Violence Assessment Tool

i. At the present time, does your partner threaten you with a weapon?

ii. At the present time, does your partner beat you so badly that you must seek medical help?

iii. At the present time, does your partner act like he or she would like to kill you?

iv. My partner has no respect for my feelings (never, rarely, occasionally, often, always).

c. Ongoing Abuse Screen (OAS) or Abuse Assessment Screen (five items). Both use the same category of items, but the OAS is targeted to ongoing IPV.

i. Are you presently emotionally or physically abused by your partner or someone important to you?

ii. Are you presently being hit, slapped, kicked, or otherwise physically hurt by your partner or someone important to you?

iii. Are you presently being forced to engage in sexual activities?

iv. Are you afraid of your partner or any one of the following (circle if applicable): husband/wife, ex-husband/ex-wife, boyfriend/girlfriend, stranger?

v. (If pregnant) Have you been hit, slapped, kicked, or otherwise physically hurt by your partner or someone important to you during pregnancy (Weiss et al., 2003)?

d. The Humiliation, Afraid, Rape, Kick (HARK) instrument

i. H-Humiliation. Within the past year, have you been humiliated or emotionally abused in other ways by your partner or your ex-partner?

ii. A-Afraid. Within the past year, have you been afraid of your partner or ex-partner?

iii. R-Rape. Within the past year, have you been raped by or forced to have any kind of sexual activity with your partner or ex-partner? iv. K-Kick. Within the past year, have you been kicked, hit, slapped, or otherwise physically hurt by your partner or ex-partner?

v. One point is given for every yes answer; a score of greater than 1 is positive for IPV (Sohal et al., 2007). 
e. The Woman Abuse Screening Tool had sensitivity of $88 \%$ and specificity of $89 \%$.

i. In general, how would you describe your relationship?

A lot of tension some tension no tension

ii. Do you and your partner work out arguments with . . .?

Great difficulty some difficulty no difficulty

iii. Do arguments ever result in you feeling put down or bad about yourself?

Often sometimes never

iv. Do arguments ever result in hitting, kicking, or pushing?

Often sometimes never

v. Do you ever feel frightened by what your partner says or does?

Often sometimes never

vi. Has your partner ever abused you physically?

Often sometimes never

vii. Has your partner ever abused you emotionally?

Often sometimes never

viii. Has your partner ever abused you sexually?

Often sometimes never

To score this instrument, the responses are assigned a number. For the first question, "a lot of tension," gets a score of 1 and the other two get a 0 . For the second question, "great difficulty" gets a score of 1 and the other two get 0 . For the remaining questions, "often" gets a score of 1 , "sometimes" gets a score of 2 , and "never" gets a score of 3 (Brown et al., 1996).

f. STAT (Slapped, Threatened, and Throw)

Have you ever been in a relationship where your partner has pushed or slapped you?

Have you ever been in a relationship where your partner has threatened you with violence?

Have you ever been in a relationship where your partner has thrown, broken, or punched things?

3. Disclosure: No screening tool should be used in lieu of good clinical judgment. As always, clinical judgment should outweigh test scores if there appears to be a discrepancy between the two. There are several considerations when a disclosure of abuse is made:

a. Respecting client confidentiality is a critical aspect of the nurse-client relationship. It is important for nurses to realize when there are ethical, professional, and legal exceptions to client confidentiality within client relationships. Although state requirements vary, nurses should be guided by the American Nurses Association (ANA) Code of Ethics and the profession's practice standards regarding confidentiality and health information.

b. Knowledge of community services and referral services; provide resources for patient safety

c. Provide emotional support; reassure the patient is not alone

d. Teach about the cycle of abuse

e. If postpartum, arrange for a home care visit if possible. Home visiting interventions addressing IPV in nonperinatal population groups have been effective in minimizing IPV and improving outcomes. This suggests that perinatal home visiting programs 
adding specific IPV interventions may reduce IPV and improve maternal and infant health.

f. Duggan et al. (2000) developed the Hawaii Healthy Start tool, which has since been validated in a number of studies. The following factors raise the risk for IPV in the perinatal setting:
i. Unmarried
ii. Partner employed
iii. Inadequate income
iv. Unstable housing
v. No phone
vi. Education less than 12 years
vii. Inadequate emergency contacts
viii. History of substance use
ix. Inadequate prenatal care
x. History of abortions
xi. History of psychiatric care
xii. Abortion unsuccessfully sought or attempted
xiii. Adoption sought or attempted
xiv. Marital or family problems
xv. History of depression

g. Hawaii Risk Indicators Screening Tool: Based on the medical record or interview; score true, false, unknown. Based on the medical record or interview, score each factor as true, false, or unknown. A positive screen: True score on item number 1, 9, or 12; two or more true scores; seven or more unknown.

\section{B. IMMUNIZATIONS DURING PREGNANCY}

The CDC has an excellent reference on immunizations in pregnancy to keep the NP updated (www.cdc.gov/vaccines/pubs/preg-guide.htm).

Risk to a developing fetus from vaccination of the mother during pregnancy is primarily theoretical. No evidence exists of risk from vaccinating pregnant individuals with inactivated virus or bacterial vaccines or toxoids. Live vaccines pose a theoretical risk to the fetus. Benefits of vaccinating pregnant individuals usually outweigh potential risks when the likelihood of disease exposure is high, when infection would pose a risk to the mother or fetus, and when the vaccine is unlikely to cause harm. Generally, live virus vaccines are contraindicated for pregnant individuals because of the theoretical risk of transmission of the vaccine virus to the fetus. If a live virus vaccine is inadvertently given to a pregnant patient, or if an individual becomes pregnant within 4 weeks after vaccination, the patient should be counseled about the potential effects on the fetus. But vaccination is not ordinarily an indication to terminate the pregnancy. Whether live or inactivated vaccines are used, vaccination of pregnant individuals should be considered on the basis of risks versus benefits, that is, the risk of the vaccination versus the benefits of protection in a particular circumstance.

Screening for rubella and hepatitis B is recommended for all pregnant individuals. Individuals susceptible to rubella should be vaccinated immediately after delivery. A patient known to be HBsAg positive should be followed up carefully to ensure that the infant receives hepatitis B immune globulin and begins the hepatitis $B$ vaccine series less than 12 hours after birth and that the infant completes the recommended hepatitis B vaccine series. No known risk 
exists for the fetus from passive immunization of pregnant individuals with immune globulin preparations.

1. Recommended during pregnancy

a. Influenza (regardless of the gestational age) during the flu season (October through March in the United States). Do not administer live attenuated influenza vaccines (LAIV) to pregnant individuals.

b. Tdap (tetanus, diphtheria, acellular pertussis administered during the late second or third trimester): all pregnant individuals should receive the Tdap (vaccine) regardless of whether or not they've had the Tdap before. If not administered during pregnancy, Tdap should be administered immediately postpartum (AAFP, 2013).

2. Contraindicated/not recommended during pregnancy
a. Anthrax
b. BCG
c. Measles
d. Mumps
e. Rubella
f. Varicella
g. Yellow fever
h. Zoster

3. Not routinely recommended (risk vs. benefit)
a. Human papillomavirus
b. Polio
c. Plague
d. Typhoid

4. Contraindicated but no adverse outcomes if given in pregnancy

a. Varicella (because the effects on the fetus are unknown, pregnant individuals should not be vaccinated)

5. Indications for vaccine that are not altered by pregnancy
a. Cholera
b. Hepatitis A
c. Hepatitis B
d. Meningococcus
e. Pneumococcus
f. Rabies
g. Tetanus, diphtheria, pertussis

i. Routine booster: If a tetanus and diphtheria booster vaccination is indicated during pregnancy for a patient who has previously not received Tdap (i.e., more than 10 years since previous $\mathrm{Td}$ ), then healthcare providers should administer Tdap during pregnancy, preferably during the third or late second trimester (after 20 weeks gestation).

ii. Wound management: If a Td booster is indicated for a pregnant individual who previously has not received Tdap, Tdap should be administered.

iii. Unknown or incomplete tetanus vaccination: To ensure protection against maternal and neonatal tetanus, pregnant individuals who never have been vaccinated against tetanus should receive three vaccinations containing tetanus and reduced diphtheria toxoids. The recommended schedule is 0 weeks, 4 weeks, and 6 to 12 months. Tdap should replace one dose of $\mathrm{Td}$, preferably during the third or late second trimester of pregnancy (after 20 weeks gestation). For pregnant individuals who have previously received a dose of Tdap, Td should be used in these situations. 
iv. Providers are encouraged to report the administration of Tdap

to pregnant individuals, regardless of trimester, to the appropriate manufacturer's pregnancy registry: for Adacel@ to Sanofi Pasteur, telephone 1-800-822-2463 and for Boostrix® to GlaxoSmithKline Biologicals, telephone 1-888-825-5249.

\section{Recommended Reading}

1. What to Expect When You Are Expecting by Eisenberg, Murkoff, Hathaway (Workman Publishing)

2. Pregnancy, Childbirth, and the Newborn by Simkin, Whalley, Deppler (Meadowbook Press)

3. Literature specific to the practice, office, or clinic

\section{Bibliography}

Alexander, E. K., Pearce, E. N., Brent, G. A., Brown, R. S., Chen, H., Dosiou, C., Grobman, W. A., Laurberg, P., Lazarus, J. H., Mandel, S. J., Peeters, R. P., \& Sullivan, S. (2017). Guidelines of the American thyroid association for the diagnosis and management of thyroid disease during pregnancy and the postpartum. Thyroid, 27, 315-389. https://doi.org/10.1089/thy.2016.0457

Alman, B. L., Coffman, E., Siega-Riz, A. M., \& Luben, T. J. (2017). Associations between maternal water consumption and birth defects in the national birth defects prevention study (20002005). Birth Defects Research Part A: Clinical and Molecular Teratology, 109, 193-202. https://doi. org/10.1002/bdra.23569

Alto, W. A. (2005). No need for glycosuria/proteinuria screen in pregnant women. Journal of Family Practice, 54, 978-983.

Alto, W. A., \& Yetman, C.A. (2007). Routine prenatal urine dipstick testing. Journal of Reproductive Medicine, 52(10), 984

American Academy of Pediatrics and American College of Obstetricians and Gynecologists. (2013). Guidelines for perinatal care (8th ed.). Author.

American Academy of Pediatrics and American College of Obstetricians and Gynecologists. (2017). Guidelines for perinatal care (8th ed.). Elk Grove Village, IL. https:/ /www.acog.org/clinical-infor mation/physician-faqs/-/media/3a22e153b67446a6b31fb051e469187c.ashx

American Association of Family Physicians. (2013). ACIP now recommending DTAP for all pregnant women. https://www.aafp.org/afp/2013/1015/p507.html

American Beverage Association. (2020, March 4). Guidance for responsible labeling and marketing of energy drinks. https: / /www.energydrinkinformation.com/resources/guidelines /

American College of Obstetricians and Gynecologists. (2013). ACOG Practice Bulletin No. 140: Management of abnormal cervical cancer screening test results and cervical cancer precursors. Obstetrics $\mathcal{E}$ Gynecology, 122(6), 1338-1367. https://doi.org/10.1097/01. AOG.0000438960.31355.9e

American College of Obstetricians and Gynecologists. (2014). Committee Opinion No. 611: Method for estimating due date. Obstetrics $\mathcal{E}$ Gynecology, 124(4), 863-866. https://doi.org/10.1097/01. AOG.0000454932.15177.be

American College of Obstetricians and Gynecologists. (2015). Vitamin D: Screening and supplementation during pregnancy (ACOG Committee Opinion No. 495). Author.

American College of Obstetricians and Gynecologists. (2020). ACOG Practice Bulletin No. 223: Thyroid disease in pregnancy. Obstetrics $\mathcal{E}$ Gynecology, 135, 3261. https://doi.org/10.1097/ AOG.0000000000003894

American College of Obstetricians and Gynecologists Committee on Obstetric Practice. (2015). Physical activity and exercise during pregnancy and the postpartum period (ACOG Committee Opinion No. 650). Author.

American Society for Colposcopy and Cervical Pathology. (2019). Updated consensus guidelines on the management of women with abnormal cervical cancer screening tests and cancer precursors. https: / / www.asccp.org/management-guidelines

Bardwell, J., Sherin, K., Sinacore, J., Zitter, R., \& Shakil, A. (1999). Screening for domestic violence in family medicine. Journal of Advocate Health Care, 1(1), 5-7.

Bishop, J. L., Northstone, K., Green, J. R., \& Thompson, E. A. (2011). The use of complementary and alternative medicine in pregnancy: Data from the Avon longitudinal study of parents 
and children. Complementary Therapeutic Medicine, 19, 303-310. https://doi.org/10.1016/j. ctim.2011.08.005

Black, C. M., Marrazzo, J., Johnson, R. E., Hook, E. W., Jones, R. B., Green, T. A., Schachter, J., Stamm, W. E., Bolan, G., St Louis, M. E., \& Martin, D. H. (2002). Head-to-head multicenter comparison of DNA probe and nucleic acid amplification tests for chlamydia trachomatis infection in women performed with an improved reference standard. Journal of Clinical Microbiology, 40, 3757-3763. https:/ /doi.org/10.1128/JCM.40.10.3757-3763.2002

Bonati, M., Bortulus, R., Marchetti, F., Romero, M., \& Tognoni, G. (1990). Drug use in pregnancy: An overview of epidemiological (drug utilization) studies. European Journal of Clinical Pharmacology, 38, 325-328. https:/ / doi.org/10.1007/BF00315569

Branson, B. M., Handsfield, H. H., Lampe, M. A., Janssen, R. S., Taylor, A. W., Lyss, S. B., \& Clark, J. E. (2006). Recommendations for HIV testing of adults, adolescents, and pregnant women in health-care setting. https://www.cdc.gov/mmwr/preview/mmwrhtml/rr5514a1.htm

Briggs, G. G., Freeman, R. K., \& Yaffee, F. J. (2011). Drugs in pregnancy and lactation: Reference guide to fetal and neonatal risk (8th ed.). Williams \& Wilkins.

Brown, J. B., Lent, B., Brett, P., Sas, G., \& Pederson, L. (1996). Development of the woman abuse screening tool for use in family practice. Family Medicine, 28, 422-428.

Center for Science in the Public Interest. (2021). Caffeine chart. https: / / cspinet.org/eating-healthy/ ingredients-of-concern/caffeine-chart

Centers for Disease Control and Prevention. (2014). Tuberculosis (TB) and pregnancy. http://www.c dc.gov/tb/publications/factsheets/specpop/pregnancy.htm

Centers for Disease Control and Prevention. (2021). Sexually transmitted infections treatment guidelines. Retrieved from https://www.cdc.gov/std/treatment-guidelines/default.htm

Chen, P. H., Rovi, S., Vega, M., Jacobs, A., \& Johnson, M. S. (2005). Screening for domestic violence in a predominantly Hispanic clinical setting. Family Practice, 22, 617-623. https://doi. org/10.1093/fampra/cmi075

Cunningham, F. G., Leveno, K. J., Bloom, S. L., Spong, C. Y., Dashe, J. S., Hoffman, B. L., Casey, B. M., \& Sheffield, J. S. (2014). William's obstetrics (24th ed.). McGraw-Hill Medical.

Davidson, M., London, M., \& Ladewig, P. (2015). Maternal newborn nursing $\mathcal{E}$ women's health across the lifespan (10th ed.). Pearson.

De Groot, L., Abalovich, M., Alexander, E. K., Amino, N., Barbour, L., Cobin, R. H., Eastman, C. J., Lazarus, J. H., Luton, D., Mandel, S. J., Mestman, J., Rovet, J., \& Sullivan, S. (2012). Management of thyroid disfunction during pregnancy and postpartum: An endocrine society clinical practice guideline. Journal of Clinical Endocrinology and Metabolism, 97, 2543-2565. https://doi. org /10.1210/jc.2011-2803

De Vigan, C., De Walle, H. E., Cordier, S., Goujard, J., Knill-Jones, R., Aymé, S., Calzolari, E., \& Bianchi, F. (1999). Therapeutic drug use during pregnancy: A comparison in four European countries. Journal of Clinical Epidemiology, 52(10), 977-982. https://doi.org/10.1016/ S0895-4356(99)00091-8

Duggan, A., Windham, A., McFarlane, E., Fuddy, L., Rohde, C., Buchbinder, S., \& Sia, C. (2000). Hawaii's healthy start program of home visiting for at-risk families: Evaluation of family identification, family engagement, and service delivery. Pediatrics, 105, 250-259.

Foster, J. (2017). Caffeine intake safety laws. Caffeine Informer. https:/ / www.caffeineinformer.com /caffeine-safety-laws

Hale, T. W. (2019). Hale's medications \& mothers' milk тм 2019: A manual of lactational pharmacology. Springer Publishing.

Huybrechts, K. F., Hernandez-Diaz, S., \& Bateman, B. T. (2020). Ondansetron use in pregnancy and congenital malformations- Reply. JAMA, 323, 2097-2098. https://doi.org/10.1001/ jama.2020.5067

Huybrechts, K. F., Hernandez-Diaz, S., Straub, L., Gray, K. J., Zhu, Y., Mogun, H., \& Bateman, B. T. (2020). Intravenous ondansetron in pregnancy and risk of congenital malformations. JAMA, 323, 372-374. https://doi.org/10.1001/jama.2019.18587

Huybrechts, K. F., Hernández-Díaz, S., Straub, L., Gray, K. J., Zhu, Y., Patorno, E., Desai, R. J., Mogun, H., \& Bateman, B. T. (2018). Association of maternal first-trimester ondansetron use with cardiac malformations and oral clefts in offspring. JAMA, 320, 2429-2437. https://doi. org/10.1001/jama.2018.18307

Institute of Medicine. (2009a). Nutrition during pregnancy: Part 1: Weight gain, Part 2: Nutrient supplements. National Academies Press. https://www.ncbi.nlm.nih.gov/books/NBK235228/

Institute of Medicine. (2009b). Weight gain during pregnancy: Reexamining the guidelines. National Academies Press. https://www.nap.edu/resource/12584/Report-Brief---Weight-Gain-DuringPregnancy.pdf

Institute of Medicine. (2011). Clinical preventive services for women: Closing the gaps. National Academies Press. https://www.nap.edu/openbook.php?record_id=13181 
Institute of Medicine. (2014). Caffeine in food and dietary supplements: Examining safety: Workshop summary. The National Academies Press. https: / www.nap.edu/catalog/18607/caffeine-in-food-a nd-dietary-supplements-examining-safety-workshop-summary

Jesse, D., \& Graham, M. (2005). Are you often sad and depressed? Brief measures to identify women at risk for depression in pregnancy. American Journal of Maternal Child Nursing, 30(1), 40-45.

Johnson, K. E. (2020). Overview of TORCH infections. http:// www.uptodate.com

Johnson, K. E., Posner, S., Biermann, J., Cordero, J. F., Atrash, H. K., Parker, C. S., Boulet, S., Curtis, M. G., CDC/ATSDR Preconception Care Work Group, \& Select Panel on Preconception Care. (2006). Recommendations to improve preconception health and health care-United States: A report of the CDC/ATSDR preconception care work group and the select panel on preconception care. MMWR Recommendations and Reports, 55(RR-6), 1-23. http:/ / www.cdc.gov/mmwr/ preview/mmwrhtml/rr5506a1.htm

Kallmyer, T. (2019, December 10). Caffeine sensitivity. Caffeine Informer. https:/ /www.caffeineinfo rmer.com/caffeine-sensitivity

Kennedy, D. (2016). Ondansetron and pregnancy: Understanding the data. Obstetric Medicine, 9(1), 28-33. https:/ /doi.org/10.1177/1753495X15621154

King, T. L., Brucker, M. C., Kriebs, J. M., Fahey, J. O., Gegor, C. L., \& Varney, H. (2015). Varney's midwifery (5th ed.). Jones \& Bartlett.

Koletzko, B., Lien, E., Agostoni, C., Bohles, H., Campoy, C., Cetin, I., Decsi, T., Dudenhausen, J. W., Dupont, C., Forsyth, S., Hoesli, I., Holzgreve, W., Lapillonne, A., Putet, G., Secher, N. J., Symonds, M., Szajewska, H., Willatts, P., Uauy, R., \& World Association of Perinatal Medicine. (2008). The roles of long-chain polyunsaturated fatty acids in pregnancy, lactation and infancy: Review of current knowledge and consensus recommendations. Journal of Perinatal Medicine, 36, 5-14. https://doi.org/10.1515/JPM.2008.001

Koren, G. (2003). Hair treatments: Drugs, pregnancy, and lactation. Ob/Gyn News, 38, 8.

LactMed $®$ Drugs and Lactation Database. (2019, June). Caffeine. National Library of Medicine. http s:/ / www.ncbi.nlm.nih.gov/books/NBK501467/

Langer, J. W. (2018, June). Expert report: Genetics, metabolism, and individual responses to caffeine. Institute for Scientific Information on Coffee. www.coffeeandhealth.org

Leviton, A. (2018). Biases inherent in studies of coffee consumption in early pregnancy and the risks of subsequent events. Nutrients, 10(9), 1152. https: / / doi.org/10.3390/nu10091152

Li, D. K., Janevic, T., Odouli, R., \& Liu, L. (2003). Hot tub use during pregnancy and the risk of miscarriage. American Journal of Epidemiology, 158, 931-937. https://doi.org/10.1093/aje/kwg243

Machtinger, R., Gaskins, A. J., Mansur, A., Adir, M., Racowsky, C., Baccarelli, A. A., Hauser, R., \& Chavarro, J. E. (2017). Association between preconception maternal beverage intake and in vitro fertilization outcomes. Fertility and Sterility, 108(6), 1026-1033. https://doi.org/10.1016/j. fertnstert.2017.09.007

Margulies, R., \& Miller, L. (2001). Fruit size as a model for teaching first trimester uterine sizing in bimanual examination. Obstetrics $\mathcal{E}$ Gynecology, 98, 341-344. https://doi.org/10.1016/ S0029-7844(01)01406-5

Martin, J. A., Hamilton, B. E., Sutton, P. D., Ventura, S. J., Menacker, F., \& Kirmeyer, S. (2006). Births: Final data for 2004. National Vital Statistics Reports, 55(1), 1-102.

National Academies of Sciences, Engineering, and Medicine. (2020). Nutrition during pregnancy and lactation: Exploring new evidence: Proceedings of a workshop. The National Academies Press. https ://www.nationalacademies.org/our-work/nutrition-during-pregnancy-and-lactation-explori ng-new-evidence-a-workshop

National Clearinghouse Guidelines. (2012). Routine prenatal care. https:/ / www.guideline.gov/sum maries/summary/38256/routine-prenatalcare?q=prenatal+care

Nehlig, A., \& Alexander, S. P. (2018). Variation in caffeine metabolism. Pharmacological Reviews, 70(2), 384-411. https:/ /doi.org/10.1124/pr.117.014407

Nelson, H. D., Bougatsos, C., \& Blazina, I. (2012). Screening women for intimate partner violence: A systematic review to update the 2004U.S. preventiveservices taskforcerecommendation. Annals of Internal Medicine, 156(11), 796-808. https:/ / doi.org/10.7326/0003-4819-156-11-201206050-00447

Olaiya, O., Sharma, A. J., Tong, V. T., Dee, D., Quinn, C., Agaku, I. T., Conrey, E. J., Kuiper, N. M., \& Satten, G. A. (2015). Impact of the 5As brief counseling on smoking cessation among pregnant clients of special supplementation nutrition program for Women, Infants, and Children (WIC) clinics in Ohio. Preventive Medicine, 81, 438-443. https://doi.org/10.1016/j.ypmed.2015.10.011

Olson, C. M. (2008). Achieving a healthy weight-gain during pregnancy. Annual Review of Nutrition, 28, 411-423. https://doi.org/10.1146/annurev.nutr.28.061807.155322

Paranjape, A., \& Liebschutz, J. (2004). STaT: A three-question screen for intimate partner violence. Journal of Women's Health, 12(3), 233-239. https: / /doi.org/10.1089/154099903321667573

Rosenfeld, L. S., Mihalov, J. J., Carlson, S. J., \& Mattia, A. (2014). Regulatory status of caffeine in the United States. Nutrition Reviews, 72, 23-33. https://doi.org/10.1111/nure.12136 
Sharps, P. W., Campbell, J., Baty, M. L., Walker, K. S., \& Bair-Merritt, M. H. (2008). Current evidence on perinatal home visiting and intimate partner violence. Journal of Obstetric, Gynecologic, and Neonatal Nursing, 37(4), 480-490. https://doi.org/10.1111/j.1552-6909.2008.00267.x

Sherin, K. M., Sinacore, J. M., Li, X. Q., Zitter, R. E., \& Shakil, A. (1998). HITS: A short domestic violence screening tool for use in a family practice setting. Family Medicine, 30(7), 508-512.

Shieh, C., \& Carter, A. (2011). Online prenatal nutrition education. Nursing for Women's Health, 15, 27-35. https://doi.org/10.1111/j.1751-486X.2011.01608.x

Sohal, H., Eldridge, S., \& Feder, G. (2007). The sensitivity and specificity of four questions (HARK) to identify intimate partner violence: A diagnostic accuracy study in general practice. $B M C$ Family Practice, 8, 49. https:/ /doi.org/10.1186/1471-2296-8-49

Sohoni, A., Bosley, J., \& Miss, J. C. (2014). Bedside ultrasonography for obstetric and gynecologic emergencies. Critical Care Clinics, 30, 207-226. https:/ / doi.org/10.1016/j.ccc.2013.10.002

Stotland, N. E., Haas, J. S., Brawarsky, P., Jackson, R. A., Fuentes-Afflick, E., \& Escobar, G. J. (2005). Body mass index, provider advice, and target gestational weight gain. Obstetrics $\mathcal{E}$ Gynecology, 105, 633-638. https:/ / doi.org/10.1097/01.AOG.0000152349.84025.35

Sweet, R., \& Gibbs, R. (2009). Infectious diseases of the female genital tract (5th ed.). Williams and Wilkins.

Thorlton, J., Ahmed, A., \& Colby, D. A. (2016). Energy drinks: Implications for the breastfeeding mother. The American Journal of Maternal Child Nursing, 41(3), 179-185. https:/ / doi.org/10.1097/ NMC.0000000000000228

Tjaden, P., \& Thoennies, N. (2000). The role of stalking in domestic violence crime reports generated by the Colorado springs police department. Violence and Victims, 15(4), 427-441. https:// doi.org/10.1891/0886-6708.15.4.427

Ulrich, Y. C., McKenna, L. S., King, C., Campbell, D. W., Ryan, J., Torres, S., Lea, P. P., Medina, M., Garza, M. A., Johnson-Mallard, V., Landenberger, K., \& Campbell, J. C. (2006). Postpartum mothers' disclosure of abuse, role, and conflict. Health Care for Women International, 27, 324-343. https://doi.org/10.1080/07399330500511733

U.S. Department of Health and Human Services-Food and Drug Administration \& Center for Food Safety and Applied Nutrition. (2018, April). Highly concentrated caffeine in dietary supplements: Guidance for industry. https://www.fda.gov/files/food/published/Guidance-for-Industry--H ighly-Concentrated-Caffeine-in-Dietary-Supplements-DOWNLOAD.pdf

U.S. Preventive Services Task Force (2019). Elevated blood lead levels in children and pregnant women: Screening. https://www.uspreventiveservicestaskforce.org/uspstf/recommendation/elevated -blood-lead-levels-in-childhood-and-pregnancy-screening

U.S. Preventive Services Task Force. (2021). Tobacco smoking cessation in adults, including pregnant persons: Interventions. Retrieved from https://www.uspreventiveservicestaskforce.org/uspstf/ recommendation/tobacco-use-in-adults-and-pregnant-women-counseling-and-interventions

WebMD. (2016). Taking medicine in pregnancy. http://www.webmd.com/baby/guide/taking -medicine-during-pregnancy\#1

Weiss, S., Ernst, A., Cham, E., \& Nick, T. (2003). Development of a screen for ongoing intimate partner violence. Violence and Victims, 18(2), 131-141. https:/ / doi.org/10.1891/vivi.2003.18.2.131

Wikoff, D., Welsh, B. T., Henderson, R., Brorby, G. P., Britt, J., Myers, E., Goldberger, J., Lieberman, H. R., O’Brien, C., Peck, J., Tenenbein, M., Weaver, C., Harvey, S., Urban, J., \& Doepker, C. (2017). Systematic review of the potential adverse effects of caffeine consumption in healthy adults, pregnant women, adolescents, and children. Food and Chemical Toxicology: An International Journal published for the British Industrial Biological Research Association, 109(Pt 1), 585-648. https:/ /doi.org/10.1016/j.fct.2017.04.002

Williams, L., Zapata, L., D’Angelo, D., Harrison, L., \& Morrow, B. (2011). Associations between preconception counseling and maternal behaviors before and during pregnancy. Maternal Child Health Journal, 16(9), 1854-1861. https:/ / doi.org/10.1007/s10995-011-0932-4

Williamson, M. A., \& Snyder, L. M. (2014). Wallach's interpretation of diagnostic tests (10th ed.). Lippincott Williams \& Wilkins. 